\title{
Pharmacotherapy for fibromyalgia
}

\author{
Howard S. Smith ${ }^{*}$, Donna Bracken ${ }^{2}$ and Joshua M. Smith ${ }^{3}$ \\ 1 Department of Anesthesiology, Albany Medical College, Albany, NY, USA \\ 2 Medical School, Albany Medical College, Albany, NY, USA \\ 3 Pharmaceutical Research Institute, Albany, NY, USA
}

\section{Edited by:}

Arpad Szallasi, Monmouth Medical

Center, USA

\section{Reviewed by:}

Marco Pappagallo, Mount Sinai School

of Medicine, USA

Tobias Moeller-Bertram, University of California, USA

Troels Jensen, Aarhus University

Hospital, Denmark

*Correspondence:

Howard S. Smith, Department of Anesthesiology, Albany Medical College, 47 New Scotland Avenue, MC-131, Albany, NY 12208, USA. e-mail:smithh@mail.amc.edu
Fibromyalgia (FM) is a chronic disorder characterized by multifocal pain and other associated somatic symptoms including fatigue, insomnia, cognitive/memory problems, and even psychological distress. It appears that $2-4 \%$ of the general population suffers from FM. FM negatively impacts the physical functioning of its patients, as evidenced by difficulties with multiple daily activities, as well as affecting emotional health, social functioning, and health related quality of life. This review will discuss the potential theories that possibly contribute to the pathogenesis of FM, although the precise mechanism is unknown. The evolution of the assessment of FM will also be examined, with the waning use of tender point examinations and the appearance of new simple, practical diagnostic criteria. Although non-pharmacologic therapeutic options (exercise, education, cognitive-behavioral therapy) have been shown to be extremely effective in FM, the focus of this article will be on pharmacologic strategies. Non-Food and Drug Administration (FDA) approved as well as FDA approved agents will be presented. Each agent's therapeutic "niche" in FM management will be discussed based on its pharmacologic profile, patient responsiveness, and tolerability. Finally a clinical algorithm will be presented for the step-wise management of pain and other associated symptoms of FM.

Keywords: pharmacotherapy, fibromyalgia, pregabalin, duloxetine, milnacipran, efficacy, pain

\section{INTRODUCTION}

Fibromyalgia (FM) is a central pain disorder that seems to involve altered afferent processing, resulting in augmentation of peripheral stimuli, especially the nociceptive types. The "core" symptoms seen in FM and many other central sensitization disorders include multifocal pain, fatigue, insomnia, cognitive/memory problems, and psychological distress. However, FM patients may experience a multitude of other symptoms, including dysesthesias, stiffness, poor balance, oral/ocular symptoms (e.g., keratoconjunctivitis sicca), headaches, sexual dysfunction, and impaired physical function (Figure 1).

Chronic widespread pain (CWP) may occur with no other associated symptoms, generally referring to persistent pain $\geq 3$ months with multiple locations in multiple extremities (usually upper and lower/right and left side of body), spine/axial skeleton, head, and/ or thoraco abdominopelvic regions. FM includes CWP, but also includes other symptoms, notably fatigue, sleep disturbance, stiffness, hyperalgesia, impaired functioning, and cognitive or memory problems.

There is growing support that FM is part of a much larger continuum that has been called many things, including functional somatic syndromes, medically unexplained symptoms, chronic multisymptom illnesses, somatoform disorders, and perhaps most appropriately, central sensitivity syndromes (CSS; Smith et al., 2011). Yunus (1984) showed FM to be associated with tension type headache, migraine, and irritable bowel syndrome (IBS). There may be a fair amount of clinical overlap between these syndromes. The more recent term CSS as proposed by Yunus (2008) is the preferred term to globally group these entities together in, because it is felt that this may represent the best nosological term at present for these syndromes [e.g., chronic fatigue syndrome, vulvodynia/ chronic pelvic pain, IBS, interstitial cystitis, temporomandibular disorder (TMD), FM].

Groups of individuals with these CSS conditions (e.g., FM, IBS, interstitial cystitis, headaches, TMD, etc.) display diffuse hyperalgesia (increased pain in response to normally painful stimuli) and/or allodynia (pain in response to normally nonpainful stimuli; Langemark et al., 1989; Maixner et al., 1995; Clauw et al., 1997; Giesecke et al., 2004, 2005; Ness et al., 2005; Rodrigues et al., 2005). Many of these conditions have also been shown to demonstrate more sensitivity to many stimuli other than pain (i.e., auditory, Gerster and Hadj-Djilani, 1984; Geisser et al., 2007, visual), and the aggregate data suggest that these individuals have a fundamental problem with pain or sensory amplification rather than an structural or inflammatory condition in the specific body region where the pain is being experienced (Smith et al., 2011).

Non-pharmacologic therapeutic options are extremely important in the management of this disorder, however we will briefly touch upon this aspect of treatment as pharmacologic strategies are the focus of this article. In this narrative review of the current available literature, the authors each separately performed a review using MEDLINE/PubMed, and EMBASE as sources in a non-systematic fashion and search terms (FM, pathophysiology, treatment, criteria). Abstracts were screened for relevance with additional sources identified via manual search of bibliographies and reference lists. The searches were restricted to the English language. Observational studies (e.g., cohort and case control studies) and open-label studies were excluded from the review. 


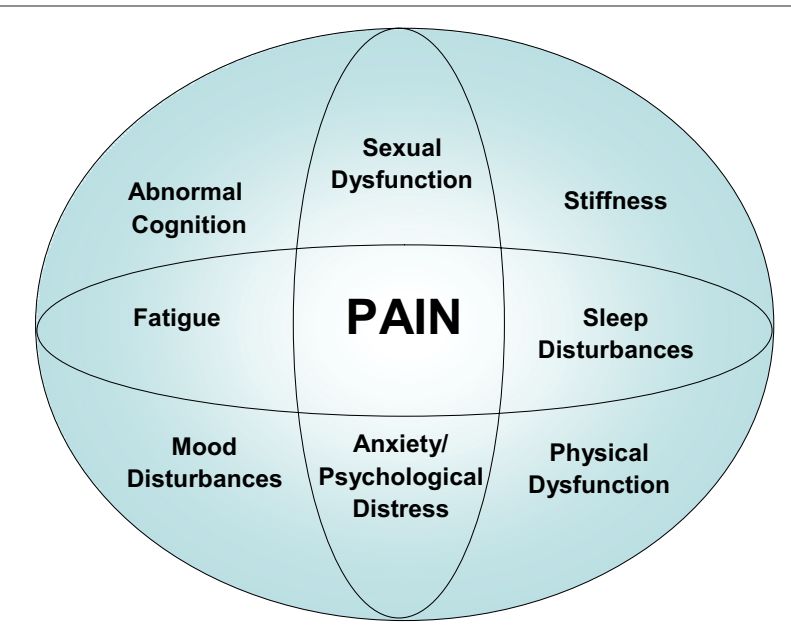

FIGURE 1 | Fibromyalgia domains.

\section{FIBROMYALGIA SYNDROME}

It appears that 2-4\% (Wolfe et al., 1995; Miedema et al., 1998) of the population suffers from FM, with the disorder being two times more prevalent among women than men. This latter statement may be attributed to the fact that women tend to be more tender than men. The disorder is predominantly diagnosed in patients aged 20-60 years (mean age, 49 years; Wolfe et al., 1995; Miedema et al., 1998). FM negatively impacts the physical functioning of its patients, as evidenced by difficulties with multiple daily activities (Bennett et al., 2007; Jones et al., 2008). Sixty-two percentage of patients have difficulty climbing stairs, $55 \%$ have difficulty walking two blocks, and $35 \%$ have difficulty with activities of daily life (ADLs; Bennett et al., 2007). FM can also negatively affect personal relationships, career, and mental health (Bernard et al., 2000).

\section{PATHOPHYSIOLOGY OF FIBROMYALGIA}

A quantitative sensory testing study in $85 \mathrm{FM}$ patients and 40 matched controls found that the patients had altered heat and cold thresholds and a reduced tolerance for pain, as well as a reduced nociceptive reflex threshold, a measure of central excitability (Desmeules et al., 2003). There appears to be significant support for central sensitization in the generation of FM symptoms (Burgmer et al., 2009; Woolf, 2011). Staud et al. (2001) showed temporal summation and after sensations of the pain elicited by repetitive cutaneous thermal stimuli and repetitive mechanical stimuli to muscles in patients with FM. Two years later, Staud et al. (2003a) found that temporal summation occurred at substantially lower forces and at a lower frequency of stimulation in FM patients than in control subjects, and that painful after sensations were greater in amplitude and more prolonged. The enhanced experimental pain in FM patients was shown to contribute to the variance of the clinical pain (Staud et al., 2003b). The year after Staud et al. (2004) showed that the maintenance of experimentally induced pain in FM patients requires significantly less frequent stimulation than in normal controls, and concluded that this heightened sensitivity to very low frequency inputs contributes to the persistent pain in these patients. Staud et al. (2007) demonstrated 3 years later that the temporal summation of pain and its maintenance was widespread, and could be equally elicited from hands or feet, leading to the conclusion that central sensitization in these patients was generalized across the neuraxis. Staud et al. also concluded that enhanced neural mechanisms in FM are not the result of selective enhancement at cortical levels (Staud et al., 2008a) and peripheral sensitization does not significantly contribute to the enhanced temporal summation of thermal pain in FM patients, based on thermal thresholds (Staud et al., 2008b).

Although there is no direct evidence, it is hypothetically conceivable that microglial activation may contribute to FM pathophysiology (Smith, 2009; Younger and Mackey, 2009). Microglial activation could lead to thalamic changes (Pattany et al., 2002; Zhao et al., 2007) with resultant abnormal processing of ascending input in FM (Smith, 2009). Thalamic changes in FM appear to be supported by neuroimaging studies (Burgmer et al., 2009; Diers et al., 2011) and altered thalamic blood flow present in chronic pain states may normalize upon pain relief (Di Piero et al., 1991; Hsieh et al., 1996). Microglial activation coupled with thalamic changes may trigger neuronal hyperexcitability which in conjunction with diminished or inefficient descending inhibitory pathways in FM [as evidenced by reduced diffuse noxious inhibitory controls (DNIC) in FM patients; Staud et al., 2003c; de Souza et al., 2009; Normand et al., 2011; or the now "preferred" term in place of DNIC, conditioned pain modulation (CPM); Yarnitsky, 2010; Yarnitsky et al., 2010], may lead to central sensitization with the subsequent development of chronic pain (Smith, 2009).

The precise mechanisms responsible for FM are unknown, but most likely involve alterations in pain and sensory processing systems. In particular, it is thought that patients with FM have inefficient descending inhibitory pathways, which normally function as endogenous analgesic systems to ameliorate pain in healthy subjects. These descending inhibitory pathways are mediated in part by the neurotransmitters serotonin and norepinephrine (Figure 2).

Studies demonstrate that patients with FM have lower cerebrospinal fluid (CSF) levels of metabolites of biogenic amines (e.g., serotonin and norepinephrine; Russell et al., 1992). Further evidence comes from treatment studies which reveal that any agent that simultaneously raises both serotonin and norepinephrine [e.g., tricyclic antidepressants (TCAs), duloxetine, milnacipran, tramadol] has been shown to be efficacious in treating FM.

In addition both the subunit genes of the serotonergic receptors, HTR3A and HTR3B, have been assessed for variations in sequence in FM patients (Coaccioli et al., 2008). However, statistical analysis determined that the various polymorphisms are probably not correlated to the disorder (Coaccioli et al., 2008). Polymorphisms in catechol-O-methyltransferase, the enzyme that inactivates catecholamines, have also been recently examined for importance in FM (Gürsoy et al., 2003). Low activity COMT genotype (LL) and intermediate activity COMT genotype (LH) were both more frequently found in FM (Gürsoy et al., 2003).

Dysregulation of dopaminergic neurotransmission has been proposed to potentially play a part in FM pathogenesis (Coaccioli et al., 2008). The pain-suppression system, activated by an acute stress, is mediated by activation of the mesolimbic dopamine neurons arising from the cell bodies of the ventral tegmental area and projecting to the nucleus accumbens (Coaccioli et al., 2008). It is proposed that exposure to prolonged stress produces both a reduction in dopamine output from the nucleus accumbens 


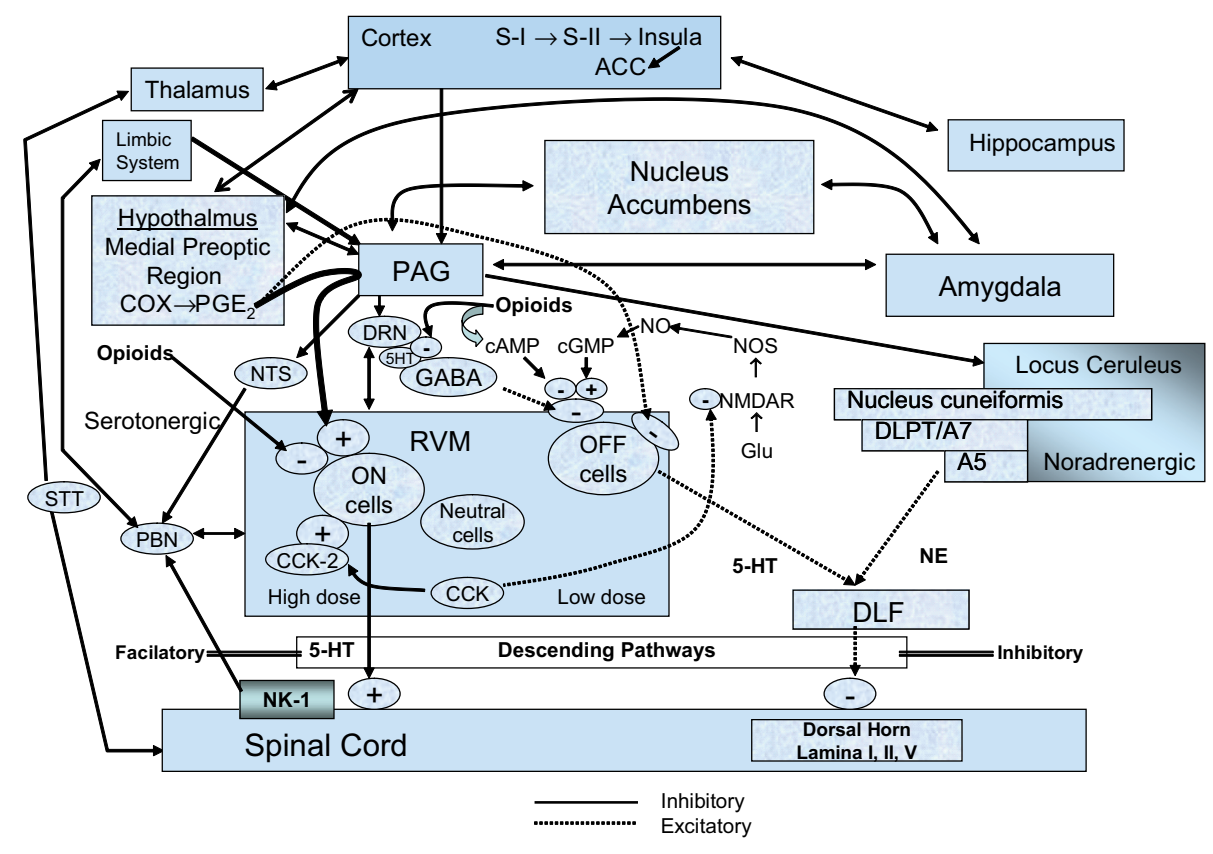

FIGURE 2 | Potential supraspinal/spinal modulation of nociception.

and the development of persistent hyperalgesia (Coaccioli et al., 2008). A pilot study examined this theory, demonstrating reduced presynaptic dopamine activity in FM patients using positron emission tomography with 6-18-fluoro-L-DOPA as a tracer (Wood et al., 2007).

Another mechanism thought to play a role in the pathophysiology of FM is the presence of augmented pain pathways in these patients. These pathways are mediated in part by substance $\mathrm{P}$ and the excitatory amino acid glutamate (Xu et al., 1992). Studies demonstrate that patients with FM have significantly higher concentrations of substance P in CSF compared with healthy subjects (Vaerøy et al., 1988; Russell et al., 1994; Bradley et al., 1996; Bradley and Alarcón, 1999; Lui et al., 2000). CSF levels of glutamate are also twice as high in patients with FM compared with healthy controls (Sarchielli et al., 2007a). Furthermore, levels of the neurotrophic factors brain-derived neurotrophic factor (BDNF) and nerve growth factor (NGF) were increased in CSF of FM patients, but was not found to be specific to FM (also found in patients with chronic migraine; Sarchielli et al., 2007b).

Other biological abnormalities exist in FM, with possible relevance to its pathophysiology. In particular, anti-inflammatory cytokines were found to be decreased in FM patients, indicating that low levels of these protective cytokines could potentially be a risk factor for FM (Uçeyler et al., 2006). Interestingly, multi-modal pain therapy appears to modify cytokine profiles in FM (Wang et al., 2008).

Brain imaging studies also support the existence of central pain augmentation in patients with FM (Gracely et al., 2002). Gracely et al. (2002) performed a study utilizing functional MRI (fMRI) in patients with FM in 2002. When stimuli of equal magnitude were administered to both FM and healthy subjects, there was increased regional blood flow in FM patients compared with controls. The regions exhibiting increased activity included the primary and secondary somatosensory cortex, the insula, and the anterior cingulate cortex, all areas which exhibit increased blood flow when normal subjects experience pain (Gracely et al., 2002).

Although it appears that the predominant mechanisms contributing to FM are largely central in nature; there may be peripheral mechanisms at play as well. Multiple studies have demonstrated differences in skin biopsies of FM patients vs. healthy controls (Kim et al., 2008) including: ballooning of Schwann cells (Kim et al., 2008), mitochondrial abnormalities (Cordero et al., 2010), and abnormal over expression of mastocytes (Blanco et al., 2010). Affaitati et al. (2011) revealed that identification and local targeted treatment of "peripheral pain generators" in the myofascial connective tissues or joints which coexisted in some patients with FM, resulted in significant benefit of the CWP of FM. Staud published that FM pain is likely to be at least partially maintained by peripheral impulse input from deep tissues, since injection of local anesthetics into painful muscles normalizes somatic hyperalgesia in FM patients (Staud et al., 2009; Staud, 2010).

\section{DIAGNOSIS AND ASSESSMENT OF FIBROMYALGIA}

The American College of Rheumatology (ACR) criteria require that an individual possess both a history of CWP and $\geq 11$ of 18 possible tender points on physical examination. However, these criteria are used predominantly for research/epidemiologic purposes. The use of tender points as diagnostic criteria is beginning to fade as it fails to recognize the presence of other symptoms that need to be addressed to optimally manage FM patient (Carville et al., 2008). Wolfe (2003) conducted a study in which they mailed surveys to 12,799 patients with either RA, osteoarthritis (OA), or FM. They found that pain present in 19 primarily non-articular sites differentiated FM from the other two disorders (Wolfe, 2003; Wilke, 2009). 
This study led to the proposal of new simple, practical criteria for the clinical diagnosis of FM. Through a multicenter study of 829 previously diagnosed FM patients and controls, the authors were able to develop a case definition of FM, develop criteria, and construct a symptom severity (SS) scale (Wolfe et al., 2010). Interestingly approximately $25 \%$ of FM patients did not satisfy the ACR criteria at the time of the study. The most important diagnostic variables were found to be the widespread pain index (WPI; a measure of the number of painful body regions) and categorical scales for cognitive symptoms, unrefreshed sleep, fatigue, and other somatic symptoms. The categorical scales were summed to create an SS scale (Wolfe et al., 2010). A new case definition of FM was developed by combining the WPI and SS scale: (WPI $\geq 7$ and SS $\geq 5$ ) or (WPI 3-6 and SS $\geq 9$; Wolfe et al., 2010). This new case definition of FM correctly classifies $88.1 \%$ of cases classified by the ACR criteria, without the use of a physical or tender point examination. The SS scale enables assessment of SS in currently or previously diagnosed FM patients, and may potentially be useful in the longitudinal evaluation of patients with marked symptom variability (Wolfe et al., 2010). It is important to note that these new criteria are certainly not meant to supplant the concept of a tender point or to not establish the presence of multifocal tenderness/mechanical hyperalgesia by a thorough physical examination.

The new American College of Rheumatology (ACR) criteria accomplish the following: remove tender points from the criteria and as the central element in the FM definition; change the case definition of FM; recognize the importance of a quantitative measure of widespread pain, the WPI; incorporate key FM symptoms into the criteria; and provide severity scales to measure the extent of widespread pain and SS (Wolfe, 2010). The new ACR criteria replace the 11 tender point dichotomy as well as the widespread pain dichotomy with the continuous WPI scale that provides much more information about pain threshold and pain extent (Wolfe, 2010). The new ACR criteria introduced the SS scale, which is a summary score from scales measuring the extent of fatigue, unrefreshed sleep, cognitive problems, and multiplicity of symptoms. The SS score correlates with the WPI at 0.733 and the tender point count at 0.680 , and is used as part of new FM criteria (Wolfe, 2010).

The Fibromyalgia Impact Questionnaire (FIQ) is a validated, disease-specific composite measure that was developed to determine the range of symptoms experienced by FM patients and responses to therapy (Bennett, 2005). It was updated in 1997 and 2002 to reflect experience with using the instrument and to clarify the scoring system (Bennett, 2005). It includes 20 questions that assess functionality with ADLs, work difficulty, general feelings of well-being, sleep quality, and the severity of symptoms including pain, fatigue, depression, anxiety, and stiffness (Bennett, 2005). Bennett et al. (2009a) performed an analysis which demonstrated that a $14 \%$ change in the FIQ total score represented a statistically and clinically meaningful difference for the patient. The results of this analysis should enhance the utility of the FIQ for clinical and research purposes (Bennett et al., 2009a).

The Revised Fibromyalgia Impact Questionnaire (FIQR) is an updated version of the FIQ that has good psychometric properties, is easy to score, and can be completed in less than $2 \mathrm{~min}$ (Bennett et al., 2009b). It has the same three domains as the FIQ: function, overall impact, and symptoms. It differs from the FIQ in that it has modified function questions and includes questions pertaining to memory, tenderness, balance, and environmental sensitivity. All questions are graded on a 0-10 numerical scale (Table 1).

Each of the three domains of the FIQR correlated well with the related domains of the FIQ $(r=0.69-0.88, p<0.01)$. The total scores of the FIQR and the FIQ were also closely correlated $(r=0.88$, $p<0.001)$. There was good correlation between the FIQR and comparable domains in the Medical Outcomes Study Short Form 36 (SF-36), with a multiple regression analysis showing that the three FIQR domain scores predicted the eight SF-36 subscale scores (Bennett et al., 2009b).

\section{NON-PHARMACOLOGIC TREATMENT OF FIBROMYALGIA}

Non-pharmacologic approaches such as exercise, education, and cognitive-behavioral therapy (CBT) have a positive impact in FM, but it is felt that these treatments appear to be underutilized in usual clinical practice (Williams, 2005; Chou et al., 2007).

Several studies have shown that exercise is beneficial in FM patients, especially with respect to reducing physical symptoms and improving functional capacity (Jones and Liptan, 2009). Exercise modalities studied included land and water aerobics, strength training, flexibility training, and various combinations of these (Jones and Liptan, 2009). The strongest evidence demonstrating benefit in FM is for aerobic and mixed-type exercises, with growing evidence for positive effects from strength training (Jones et al., 2002; Figueroa et al., 2008; Valkeinen et al., 2008; Thomas and Blotman, 2010). Busch et al. (2008) systematically reviewed 34 studies assessing the efficacy of exercise in FM. Metaanalysis of six of those studies provided moderate-quality evidence that aerobic-only exercise at intensity levels recommended by the American College of Sports Medicine has positive effects on global-well-being, physical functioning, and potentially on pain (Busch et al., 2008).

Patient education has also been analyzed as a therapeutic option for FM patients. Rooks et al. (2007) completed a randomized controlled trials (RCT) with 207 participants with FM who were randomized to four groups: (1) aerobic and flexibility training group; (2) strength, aerobic, and flexibility training group; (3) the Fibromyalgia Self-Help Course; or (4) a combination of the previous three. The combination group was found to provide the most benefit (Rooks et al., 2007). Thus, education may be useful for FM patients when utilized with other multi-modal interventions.

Cognitive-behavioral therapy combines aspects of both cognitive and behavioral interventions. Catastrophic thoughts, which are beliefs that the worst possible outcome is going to occur, is associated with increased pain severity, reduced functional capacity, and affective distress in FM patients (Giesecke et al., 2005). Cognitive therapy focuses on taking catastrophic thoughts and reframing them into more positive beliefs (Hassett and Gevirtz, 2009). Behavioral therapy, in contrast, stresses the importance of operant behavioral change over inner thoughts and feelings (Hassett and Gevirtz, 2009). Its goals are to increase adaptive behavior through positive and negative reinforcement, and to extinguish maladaptive behavior through punishment (Hassett and Gevirtz, 2009). Studies have demonstrated that both OBT and CBT are effective modalities in treating FM (Thieme et al., 2006; Thieme and Gracely, 2009). 
Table 1 | Revised Fibromyalgia Impact Questionnaire (FIOR).

Domain 1 directions: for each of the following nine questions, check the one box that best indicates how much your fibromyalgia made it difficult to do each of the following activities over the past 7 days

\begin{tabular}{lllllllllllllll}
\hline Brush or comb your hair & No difficulty & $\square$ & $\square$ & $\square$ & $\square$ & $\square$ & $\square$ & $\square$ & $\square$ & $\square$ & $\square$ & $\square$ & Very difficult \\
Walk continuously for $20 \mathrm{~min}$ & No difficulty & $\square$ & $\square$ & $\square$ & $\square$ & $\square$ & $\square$ & $\square$ & $\square$ & $\square$ & $\square$ & $\square$ & Very difficult \\
Prepare a homemade meal & No difficulty & $\square$ & $\square$ & $\square$ & $\square$ & $\square$ & $\square$ & $\square$ & $\square$ & $\square$ & $\square$ & $\square$ & Very difficult \\
Vacuum, scrub, or sweep floors & No difficulty & $\square$ & $\square$ & $\square$ & $\square$ & $\square$ & $\square$ & $\square$ & $\square$ & $\square$ & $\square$ & $\square$ & Very difficult \\
Lift and carry a bag full of groceries & No difficulty & $\square$ & $\square$ & $\square$ & $\square$ & $\square$ & $\square$ & $\square$ & $\square$ & $\square$ & $\square$ & $\square$ & Very difficult \\
Climb one flight of stairs & No difficulty & $\square$ & $\square$ & $\square$ & $\square$ & $\square$ & $\square$ & $\square$ & $\square$ & $\square$ & $\square$ & $\square$ & Very difficult \\
Change bed sheets & No difficulty & $\square$ & $\square$ & $\square$ & $\square$ & $\square$ & $\square$ & $\square$ & $\square$ & $\square$ & $\square$ & $\square$ & Very difficult \\
Sit in a chair for 45 min & No difficulty & $\square$ & $\square$ & $\square$ & $\square$ & $\square$ & $\square$ & $\square$ & $\square$ & $\square$ & $\square$ & $\square$ & Very difficult \\
Go shopping for groceries & No difficulty & $\square$ & $\square$ & $\square$ & $\square$ & $\square$ & $\square$ & $\square$ & $\square$ & $\square$ & $\square$ & $\square$ & Very difficult
\end{tabular}

Domain 2 directions: for each of the following two questions, check the one box that best describes the overall impact of your fibromyalgia over the past 7 days

\begin{tabular}{lllllllllllllll}
\hline $\begin{array}{l}\text { Fibromyalgia prevented me from } \\
\text { accomplishing goals for the week }\end{array}$ & Never & $\square$ & $\square$ & $\square$ & $\square$ & $\square$ & $\square$ & $\square$ & $\square$ & $\square$ & $\square$ & $\square$ & Always \\
I was completely overwhelmed by & Never & $\square$ & $\square$ & $\square$ & $\square$ & $\square$ & $\square$ & $\square$ & $\square$ & $\square$ & $\square$ & $\square$ & Always
\end{tabular}

my fibromyalgia symptoms

Domain 3 directions: for each of the following 10 questions, check the one box that the best indicates the intensity of your fibromyalgia symptoms over the past 7 days

Please rate your level of pain

Please rate your level of energy

Please rate your level of stiffness

Please rate the quality of your sleep

Please rate your level of depression

Please rate your level of memory problems

Please rate your level of anxiety

Please rate your level of tenderness to touch

Please rate your level of balance problems

Please rate your level of sensitivity to loud

noises, bright lights, odors, and cold

$\begin{array}{lllllllllllll}\text { No pain } & \square & \square & \square & \square & \square & \square & \square & \square & \square & \square & \square & \text { Unbearable pain } \\ \text { Lots of energy } & \square & \square & \square & \square & \square & \square & \square & \square & \square & \square & \square & \text { No energy } \\ \text { No stiffness } & \square & \square & \square & \square & \square & \square & \square & \square & \square & \square & \square & \text { Severe stiffness } \\ \text { Awoke rested } & \square & \square & \square & \square & \square & \square & \square & \square & \square & \square & \square & \text { Awoke very tired } \\ \text { No depression } & \square & \square & \square & \square & \square & \square & \square & \square & \square & \square & \square & \text { Very depressed } \\ \text { Good memory } & \square & \square & \square & \square & \square & \square & \square & \square & \square & \square & \square & \text { Very poor memory } \\ \text { No anxious } & \square & \square & \square & \square & \square & \square & \square & \square & \square & \square & \square & \text { Very anxious } \\ \text { No tenderness } & \square & \square & \square & \square & \square & \square & \square & \square & \square & \square & \square & \text { Very tender } \\ \text { No imbalance } & \square & \square & \square & \square & \square & \square & \square & \square & \square & \square & \square & \text { Severe imbalance } \\ \text { No sensitivity } & \square & \square & \square & \square & \square & \square & \square & \square & \square & \square & \square & \text { Extreme sensitivity }\end{array}$

Scoring:

Step 1. Sum the scores for each of the three domains (function, overall, and symptoms).

Step 2. Divide domain 1 score by three, divide domain 2 score by one (that is, it is unchanged), and divide domain score 3 by two.

Step 3. Add the three resulting domain scores to obtain the total Revised Fibromyalgia Impact Questionnaire score.

Adapted from Bennett et al. (2009a).

Bernardy et al. (2010) recently performed the first meta-analysis of the efficacy of CBT in FM. The systematic review included 14 out of 27 studies with 910 subjects and a median treatment time of $27 \mathrm{~h}$ over a median time range of 9 weeks. The primary endpoints were pain, sleep, fatigue, and health related quality of life (HRQOL). Secondary endpoints included depressed mood, self-efficacy pain, and healthcare-seeking behavior (Bernardy et al., 2010). They demonstrated that CBT reduced depressed mood and self-efficacy pain post-treatment, but had no significant effects on pain, fatigue, sleep, or HRQOL after treatment or at follow-up. Furthermore, OBT was shown to significantly reduce the number of physician visits at follow-up. Thus CBT may be most beneficial in helping FM patients cope with pain and depression on their own and somewhat reduce dependence on health care providers (Bernardy et al., 2010).

\section{PHARMACOLOGIC TREATMENT OF FIBROMYALGIA}

The majority of clinical trials evaluating FM therapy have included antidepressants of one class or another, especially the older, TCAs. Amitriptyline is a TCA tertiary amine with prominent therapeutic effects from monoamine reuptake (serotonin > norepinephrine) and anticholinergic/sedative side effects mediated by receptor affinity at acetylcholine, muscarinic, and histamine 1 receptors (Smith and Barkin, 2010; Figure 3).

Its usual half-life is $31-46 \mathrm{~h}$, and its metabolism is through CYP450 2C19, 1A2, and 2D6 (Smith and Barkin, 2010).

Uçeyler et al. (2008) performed a meta-analysis on the efficacy of antidepressants for treating FM. The authors found amitriptyline, studied in $13 \mathrm{RCTs}$, to provide a moderate magnitude of relief to FM patients (pain reduction by mean of $26 \%$, improvement in QOL by 30\%; Uçeyler et al., 2008). 


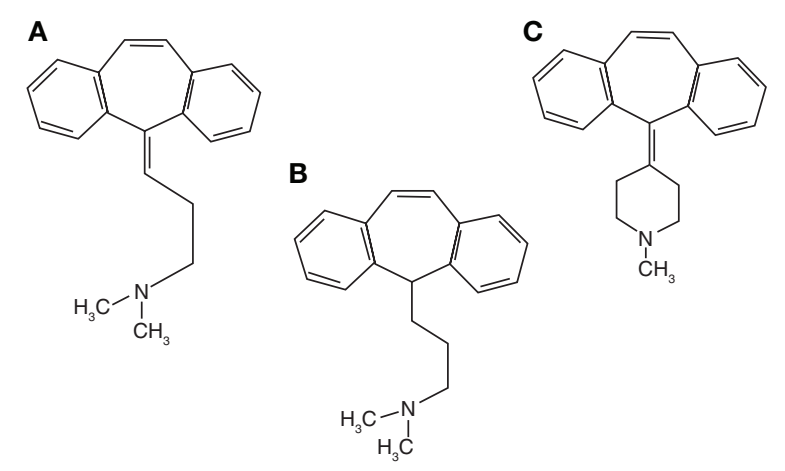

FIGURE 3 | Chemical structures of cyclobenzaprine (A), amitriptyline (B), and cyproheptadine (C).

Nishishinya et al. (2008) recently performed a systematic review specifically on the efficacy of amitriptyline in the treatment of FM. Ten RCTs were identified, and the overall study quality was moderate to high (Nishishinya et al., 2008). Amitriptyline $25 \mathrm{mg} /$ day ( $\mathrm{six}$ RCTs) demonstrated a therapeutic response compared with placebo in the domains of pain, sleep, fatigue, and overall patient and investigator impression (Nishishinya et al., 2008). This benefit was generally seen at 6-8 weeks of treatment but no significant effect was observed at 12 weeks (Nishishinya et al., 2008). Amitriptyline $50 \mathrm{mg} /$ day (four RCTs) did not appear to demonstrate a significant therapeutic effect compared with placebo (Nishishinya et al., 2008). Neither dose of amitriptyline seemed to have an effect on tender point count (Nishishinya et al., 2008). The authors concluded that there is some evidence to support the short-term efficacy of amitriptyline $25 \mathrm{mg} /$ day in FM (Nishishinya et al., 2008). However, there appeared to be no significant evidence to support the efficacy of amitriptyline at higher doses or for periods $>8$ weeks (Nishishinya et al., 2008).

Cyclobenzaprine is a centrally acting muscle relaxant which has a TCAs nucleus analog similar to amitriptyline and imipramine (Smith and Barkin, 2010; Figure 3). It exhibits norepinephrine and serotonin reuptake blockade as well as central and peripheral anticholinergic effects. The usual half-life is $32 \mathrm{~h}$ in capsules and $18 \mathrm{~h}$ in tablets. Metabolism of cyclobenzaprine is by CYP 3A4, 1A2, and 2D6 (Smith and Barkin, 2010). Cyclobenzaprine has been used to treat the musculoskeletal component and improves sleep in FM patients (Goldenberg, 1989).

Tofferi et al. (2004) systematically reviewed the effectiveness of cyclobenzaprine in the treatment of FM. Five randomized, placebo-controlled trials were identified. Endpoints included global improvement, treatment effects on pain, fatigue, sleep, and tender points over time. The odds ratio for global improvement with therapy was 3.0 [ $95 \%$ confidence interval (95\% CI) 1.6-5.6] with a pooled risk difference of 0.21 (95\% CI 0.09-0.34), which calculates to 4.8 (95\% CI 3.0-11) individuals needing treatment for one patient to experience symptom improvement. Pain improved early on, but there did not appear to be any significant improvement in fatigue or tender points at any time. The authors concluded that cyclobenzaprine-treated patients were three times as likely to report overall improvement and to report moderate reductions in individual symptoms, particularly sleep (Tofferi et al., 2004).
Most TCAs increase CNS levels of serotonin and norepinephrine by directly blocking their reuptake. Many TCAs bind to multiple receptors, and thus may have many adverse effects, especially at higher doses. In general, secondary amines (e.g., nortriptyline, desipramine) are tolerated somewhat better than tertiary amines (e.g., amitriptyline, imipramine, doxepin). Tolerability can be improved by starting at lower doses (e.g., $10 \mathrm{mg}$ of amitriptyline or $5 \mathrm{mg}$ of cyclobenzaprine), giving the dose shortly before bedtime, and gradually increasing the titration over time.

It appears that selective serotonin reuptake inhibitors (SSRIs) in general are poor agents in producing analgesia in most pain states. Highly SSRIs (e.g., citalopram) have not been shown to produce significant analgesia. Otto et al. (2008) conducted a randomized, double-blinded, placebo-controlled, cross-over trial to evaluate if escitalopram $20 \mathrm{mg}$ would relieve pain in painful neuropathy. Total pain and various pain symptoms were reduced during the treatment $(p=0.001-0.024)$. The number needed to treat (NNT) to obtain good/complete pain relief was 6.8 (Otto et al., 2008). Otto demonstrated that escitalopram did possess pain-alleviating properties in painful neuropathy, but a clinically relevant effect was found in only a few patients. Therefore, he concluded that escitalopram should not be recommended as a standard treatment in neuropathic pain (Otto et al., 2008). SSRIs that are less selective for serotonin reuptake (e.g., fluoxetine, paroxetine, sertraline) may somewhat affect norepinephrine reuptake and provide some relief in FM, but at higher than average doses as they are less potent than TCAs or serotonin-norepinephrine reuptake inhibitors (SNRIs; Fishbain et al., 2000).

Most of the SNRIs clinically available for the treatment of FM have more of a significant impact on serotonin compared with norepinephrine activity. SNRIs tend to be better tolerated than older TCAs. Venlafaxine, the first SNRI available in the US, tends to have clinically significant effects on norepinephrine reuptake only when used at higher doses (Sayar et al., 2003).

Sayar et al. (2003) conducted a study to evaluate the efficacy of venlafaxine in the treatment of patients with FM. Fifteen patients with FM were assessed prior to and after treatment with fixed-dose venlafaxine $75 \mathrm{mg} /$ day for 12 weeks. Primary endpoints were the FIQ total score and pain score. The authors found a significant improvement in the mean intensity of pain $(F=14.3 ; p=0.0001)$ and in the disability caused by FM $(F=42.7 ; p=0.0001)$. Thus, venlafaxine could potentially be beneficial in FM patients when used at these higher doses (Sayar et al., 2003).

Duloxetine and milnacipran are two SNRIs that are approved by the Food and Drug Administration (FDA) for the treatment of FM in the US (in 2008 and 2009, respectively).

Duloxetine inhibits serotonin reuptake significantly more than norepinephrine reuptake (in an approximate 10:1 ratio; Stahl et al., 2005). The standard dosing to aim for is $60 \mathrm{mg} / \mathrm{day}$, which in selected patients can be increased to $120 \mathrm{mg} /$ day based on responsiveness and tolerability. Duloxetine is the $(+)-(\mathrm{S})$ isomer of the racemic mixture with structural similarities to both fluoxetine and atomoxetine (Smith and Barkin, 2010). It possesses a secondary amine structure unlike venlafaxine, the first approved SNRI, which possesses a tertiary amine structure. It has a usual half-life of 8-17 h. Its metabolic pathways include cytochrome P450 1A2 and 2 D6. Approximately $70 \%$ of duloxetine is renally excreted as 
metabolites, with $<1 \%$ as the parent compound. Metabolites found in plasma and urine include 4-hydroxy duloxetine glucuronide and 5-hydroxy, 6-methoxy duloxetine sulfate, neither of which appear to be significantly pharmacologically active (Curran, 2009). Approximately 20\% of duloxetine is excreted in the feces, possibly representing hepatobiliary secretion. Duloxetine exhibits a high degree of protein binding (90\%) and binds primarily to albumin and alpha-1-acid glycoprotein (Smith and Barkin, 2010).

Arnold et al. (2004) conducted a multicenter (18 centers), randomized, double-blinded, placebo-controlled trial assessing the efficacy of duloxetine in FM patients with or without concurrent major depressive disorder (MDD). After single-blinded placebo treatment for 1 week, patients were randomized to either duloxetine $60 \mathrm{mg}$ twice daily $(n=104)$ or placebo $(n=103)$ for 12 weeks. Co-primary endpoints included the FIQ total score and FIQ pain score. Compared with placebo-treated subjects, duloxetine-treated subjects improved significantly more $(p=0.027)$ on the FIQ total score, but not significantly more on the FIQ pain score $(p=0.130)$. The FIQ pain score, however, might be limited in its capacity as an endpoint in that subjects must recall and rate their pain over the prior week, which may be more difficult to recall than pain over the past $24 \mathrm{~h}$ (Arnold et al., 2004).

Another multicenter (21 centers), randomized, double-blinded, placebo-controlled trial conducted by Arnold et al. (2005) assessed the efficacy of duloxetine exclusively in the treatment of females with or without MDD. The women were randomized to one of three treatment groups for a 12-week duration: duloxetine $60 \mathrm{mg} /$ day $(n=118)$, duloxetine $60 \mathrm{mg}$ twice daily $(n=116)$, or placebo $(n=120)$. The primary endpoint was pain severity as measured by the BPI average pain severity score. Compared with placebo, both duloxetine-treated groups improved significantly more $(p<0.001)$ on the BPI average pain severity score. A significantly higher percentage of duloxetine-treated patients had a decrease of $\geq 30 \%$ in this score [duloxetine $60 \mathrm{mg} /$ day $(55 \%$; $p<0.001)$; duloxetine $60 \mathrm{mg}$ twice daily (54\%; $p=0.002)$; placebo (33\%); Arnold et al., 2005].

A third study conducted by Russell et al. (2008) also examined the efficacy of duloxetine for reducing pain severity in patients with or without current MDD over a 6-month period. It was a multicenter, randomized, double-blinded, placebo-controlled trial in which 520 patients were randomized to one of four groups: duloxetine $20 \mathrm{mg} /$ day, $60 \mathrm{mg} /$ day, $120 \mathrm{mg} /$ day, or placebo. The co-primary endpoints were the BPI average pain severity score and PGI-I score. Compared with placebo, patients treated with duloxetine $120 \mathrm{mg} /$ day improved significantly more on the co-primary endpoints at 3 months [change in BPI score $(-2.31$ vs. $1.39, p<0.001)$ and PGI-I score $(2.89$ vs. $3.39, p=0.004)]$ and at 6 months [change in BPI score $(-2.26$ vs. $1.43, p=0.003)$ and PGI-I score $(2.93$ vs. $3.37, p=0.012)]$. Compared with placebo, patients treated with duloxetine $60 \mathrm{mg} /$ day also demonstrated significantly improved co-primary endpoints at 3 months and BPI score at 6 months (Russell et al., 2008).

A study conducted by Chappell et al. (2009a) evaluated the efficacy of duloxetine in FM over a 1-year period. It was a Phase III study which consisted of an 8-week open-label period followed by a 52 -week double-blinded period. Patients received duloxetine $30 \mathrm{mg} /$ day for 1 week, then $60 \mathrm{mg}$ /day for 7 weeks, and were subsequently randomized to either 60 or $120 \mathrm{mg} /$ day. The endpoints included the BPI average pain severity and interference item scores, the FIQ total score, the PGI-I score, the CGI-I score, the mean of the tender points pain thresholds, the number of tender points with a low threshold $\left(\leq 4 \mathrm{~kg} / \mathrm{cm}^{2}\right)$, and the SDS. Significant pain reduction was observed as assessed by numerous endpoints during the open-label phase of the study. This reduction in pain severity persisted throughout the double-blinded phase, as evidenced by additional mean decreases in the BPI average pain score within both duloxetine groups (Chappell et al., 2009a).

Another study conducted by Chappell et al. (2009b) analyzed the effectiveness of duloxetine $(n=162)$ compared with placebo $(n=168)$ in the treatment of FM patients for 6 months. It was a Phase III, parallel, double-blinded, placebo-controlled trial in which patients were initially randomized to duloxetine $60 \mathrm{mg} /$ day or placebo. The co-primary endpoints were BPI average pain score and the PGI-I score. The BPI average score and PGI-I score both demonstrated greater numerical improvement in duloxetinetreated compared with placebo-treated groups, but the differences were not statistically significant (BPI average score $p=0.053$, PGI-I $p=0.073$ ). However, a significant treatment-by-investigator interaction was observed for these variables which could not be fully explained. Duloxetine-treated patients did improve significantly on secondary endpoints which can be considered important factors in assessing treatment efficacy in patients with FM (Chappell et al., 2009b).

Arnold et al. (2009) pooled data from four of the prior RCTs so as to enable the assessment of precise treatment effects. Changes in the BPI average pain severity scores demonstrated significantly greater improvement in duloxetine-treated vs. placebo-treated patients at week 1 and continuing through week $12(p<0.001)$. Duloxetine also showed significantly greater improvement compared with placebo on the BPI severity scores for least pain, worst pain, and pain right now and on the mean of the pain interference scores. Finally, duloxetine was statistically superior to placebo with respect to improvement in CGI-S scores $(p<0.001)$, FIQ total scores $(p<0.001)$, HAMD $_{17}$ total scores $(p=0.003)$, PGI-I scores $(p<0.001)$, and QOL endpoints. The authors concluded that duloxetine $60-120 \mathrm{mg}$ /day effectively improved FM symptoms and may offer benefits beyond pain relief, as evidenced by improvement in secondary endpoints (Arnold et al., 2009).

Choy et al. (2009) pooled data from the prior five RCTs to reliably assess the safety and tolerability of duloxetine in the treatment of patients with FM. The most commonly reported pooled treatment emergent adverse events (TEAEs) with duloxetine were nausea $(33.4 \%)$, headache $(25.2 \%)$, dry mouth (19.2\%), insomnia (16.9\%), fatigue (12.3\%), constipation (16.7\%), diarrhea (12.9\%), and dizziness (15.1\%). Most TEAEs were mild to moderate in severity and emerged early in treatment. About $20 \%$ of patients discontinued due to TEAEs in both the short-term and 1-year studies. Serious adverse events (SAEs) were uncommon, and there were no significant differences in SAEs between groups. Mean changes in vital signs and weight were small. Although duloxetine's noradrenergic effect suggests that it may slightly increase heart rate, only $0.5 \%$ of patients in the 3 - and 6 -month studies, $0.1 \%$ of patients enrolled for 6 months or more, and $0.6 \%$ of patients in the 1 -year study had a clinically relevant increase in pulse rate. Rates of clinically significant laboratory and EKG changes were low, with the exception of ALT values being greater than five times the upper 
limit of normal in duloxetine-treated patients $(0.6 \%)$ compared with placebo-treated patients $(0 \%)$. However, the lack of cases that met criteria for Hy's rule during either short- or long-term use suggests that the risk of hepatotoxicity for duloxetine in FM is very low. In the 1-year study, four patients (1.1\%) had suicide-related behavior. However, without the presence of a placebo, this rate is difficult to interpret, especially because high rates of suicide have been demonstrated for patients with widespread pain syndromes like FM (Choy et al., 2009).

Milnacipran is the only currently FDA approved SNRI that inhibits norepinephrine reuptake more than serotonin reuptake. The standard dosing to aim for is $100 \mathrm{mg} /$ day (50 mg BID), which in selected patients can be increased to $200 \mathrm{mg}$ /day based on responsiveness and tolerability. Milnacipran is a chiral compound with an active portion being the $\mathrm{D}$-isomer (Smith and Barkin, 2010). The usual half-life of milnacipran is $6-8 \mathrm{~h}$ for the parent compound and 8-10 h for D-milnacipran, the active isomer; thus twice-daily dosing is recommended. Milnacipran's metabolism has a limited hepatic contribution and is eliminated primarily by glucuronidation to an inactive metabolite. Elimination is predominantly renal (50-60\% as unchanged parent compound in urine) with a small amount excreted in the feces (5\% or less; Smith and Barkin, 2010). Early studies demonstrated milnacipran's efficacy for treating pain and other associated symptoms of FM (Vitton et al., 2004; Gendreau et al., 2005).

Arnold et al. (2010) conducted a study assessing the efficacy of milnacipran for the treatment of FM. It was a 12-week, doubleblinded, placebo-controlled trial in which 1,025 patients were randomized to milnacipran $100 \mathrm{mg} /$ day $(n=516)$ or placebo $(n=509)$. Patients underwent 4-6 weeks of flexible-dose escalation followed by 12 weeks of stable-dose treatment. Two composite responder definitions were utilized as primary endpoints. The 2-measure composite responders achieved $\geq 30 \%$ improvement in pain and a rating of "very much improved" or "much improved" on the PGI-C (Change) scale. The 3-measure composite responders satisfied the above criteria while also demonstrating improvement on the SF-36 Physical Component Summary score. A significantly greater proportion of milnacipran-treated patients compared with placebotreated patients showed statistically significant improvements, as evidenced by 2 -measure composite responder criteria $(p<0.001)$ and 3-measure composite responder criteria $(p<0.001$; Arnold et al., 2010).

Branco et al. (2010) performed a randomized, double-blinded, placebo-controlled, multicenter study examining the effectiveness of milnacipran in the treatment of FM. Eight hundred eighty-four patients were randomized to placebo $(n=449)$ or milnacipran $200 \mathrm{mg} /$ day $(n=435)$ for 17 weeks. The primary endpoint was a 2-measure composite responder analysis. If the responder analysis was positive, FIQ was included as an additional primary endpoint. At the end of week 16, milnacipran $200 \mathrm{mg} /$ day showed significant improvements compared with placebo in the 2-measure composite responder criteria $(p=0.0003)$ and FIQ total score $(p=0.015$; Branco et al., 2010).

In an article by Goldenberg et al. (2010) the authors wanted to assess the durability of the therapeutic response to milnacipran for FM via a randomized, double-blinded, 6-month extension study. A total of 449 patients who successfully completed a 6-month lead-in study enrolled in this 6-month extension study. Patients initially receiving milnacipran $200 \mathrm{mg}$ /day during the lead-in study were maintained at this dose $(n=209)$. Patients initially assigned to placebo or milnacipran $100 \mathrm{mg} /$ day were re-randomized to two groups: $100 \mathrm{mg} /$ day $(n=48)$ or $200 \mathrm{mg} /$ day $(n=192)$ of milnacipran for an additional 6 months. Endpoints included visual analog pain ratings, FIQ total score, and PGI-C score. Patients continuing on milnacipran demonstrated a sustained reduction in pain over the entire 12-month period. Additional benefits were maintained as evidenced by FIQ and PGI-C scores. Patients initially assigned to placebo or milnacipran $100 \mathrm{mg}$ /day and re-randomized to milnacipran $200 \mathrm{mg} /$ day experienced further improvements in mean pain scores, FIQ total scores, and PGI-C scores at 1-year (Goldenberg et al., 2010).

Mease et al. (2009) performed a study which evaluated the efficacy of milnacipran in the treatment of FM. It was a 27 -week, double-blinded, multicenter trial in which 888 patients were randomized to one of three groups: placebo, $100 \mathrm{mg} /$ day, or $200 \mathrm{mg} /$ day of milnacipran. "FM responders" were considered 3-measure composite responders, while "FM pain responders" were considered 2-measure composite responders. After 3-month stable-dose treatment, a significantly higher percentage of milnacipran-treated patients met criteria as FM responders vs. placebo-treated patients (milnacipran $200 \mathrm{mg} /$ day, $p=0.017$; milnacipran $100 \mathrm{mg} / \mathrm{day}$, $p=0.028)$. A significantly higher percentage of patients treated with milnacipran $200 \mathrm{mg} /$ day also met criteria as FM pain responders vs. placebo-treated patients $(p=0.032)$. Significant pain reductions were observed after week 1 with both milnacipran doses (Mease et al., 2009).

Clauw et al. (2008) conducted a study which analyzed the effectiveness of milnacipran for the treatment of FM over a 15-week period. It was a multicenter, double-blinded, placebo-controlled trial in which 1,196 patients were randomized to either placebo $(n=401)$, milnacipran $100 \mathrm{mg} /$ day $(n=399)$, or $200 \mathrm{mg} /$ day $(n=396)$. The two primary endpoints were rates of FM composite responders and FM pain composite responders. Compared with placebo, significantly greater proportions of milnacipran-treated subjects were FM composite responders (100 mg/day: $p=0.01$; $200 \mathrm{mg} /$ day: $p=0.02$ ) and FM pan composite responders (100 mg/ day: $p=0.03 ; 200 \mathrm{mg} /$ day: $p=0.004)$. Furthermore, milnacipran was shown to significantly improve pain after 1 week of treatment (100 mg/day: $p=0.004 ; 200 \mathrm{mg} /$ day: $p=0.04$; Clauw et al., 2008).

Finally, Geisser et al. (2011) pooled results from two of the prior RCTs to determine more precise treatment effects for milnacipran in FM. Once again the primary endpoints were a 2- and 3-measure composite response analysis. Additionally, a pooled analysis of mean changes from baseline pain scores was conducted in order to evaluate the effectiveness of milnacipran over time. At 3 months, composite responder rates were significantly higher in milnacipran-treated subjects compared with placebo-treated subjects (2- and 3-measure composite responder analyses: $p \leq 0.001$, both doses vs. placebo). These improvements were not dependent upon baseline pain severity. Similar composite responder results were observed in patients who continued treatment for up to 6 months. Significant improvements in mean pain scores were seen with both doses of milnacipran compared with placebo as early as 1 week after treatment and were sustained for up to 6 months (Geisser et al., 2011). 
In the pooled analysis of data the most commonly reported adverse events with milnacipran treatment were nausea $(100 \mathrm{mg} /$ day $34.5 \%$, $200 \mathrm{mg} /$ day $40.1 \%$, placebo $20.4 \%$ ), headache (100 mg/day $18.6 \%, 200 \mathrm{mg} /$ day $18.3 \%$, placebo $14.1 \%$ ), and constipation (100 mg/day 16.2\%, $200 \mathrm{mg} /$ day 16.1\%, placebo $4.0 \%$; Geisser et al., 2011). Greater than $90 \%$ of the adverse events reported in each treatment group were classified as either mild or moderate in severity. Furthermore, milnacipran treatment did result in slight increases in heart rate $(100 \mathrm{mg} /$ day $5.5 \%$, $200 \mathrm{mg} /$ day $6.5 \%$, placebo $1.1 \%$ ) and blood pressure (100 mg/ day $6.6 \%, 200 \mathrm{mg} /$ day $4.5 \%$, placebo $1.9 \%$ ). Patients at 6-month visits who received milnacipran 100 and $200 \mathrm{mg} /$ day tended to lose more weight $(-1.16$ and $-0.97 \mathrm{~kg}$, respectively) compared with patients receiving placebo $(-0.06 \mathrm{~kg} ; p<0.05$, both doses vs. placebo; Geisser et al., 2011).

Pregabalin, approved for the treatment of FM in the US in 2007, is a gamma-aminobutyric acid (GABA) analog which binds to the alpha-2-delta subunit of calcium ion channels. The half-life of pregabalin is $5.5-6.7 \mathrm{~h}$ in the presence of a normal $\mathrm{CrCl}$ (Smith and Barkin, 2010). The dosing for this agent, however, is dependent upon the patient's $\mathrm{CrCl}$ because elimination is a function of renal clearance. Decremental dosing changes are recommended in patients with impaired renal function. Dosing secondary to side effects is based on 1-week intervals focusing on patient responsiveness and tolerability. Pregabalin's metabolism is negligible (not by CYP450 or Phase II metabolism; Barkin, 2008). Its metabolite is an $\mathrm{N}$-methylated derivative. It is renally excreted, with $98 \%$ or greater as the unchanged parent compound. No plasma protein binding has been reported (Smith and Barkin, 2010).

Crofford et al. (2005) conducted a study in which the efficacy of pregabalin for the treatment of FM was evaluated. It was a multicenter, double-blinded, placebo-controlled trial in which 529 patients were randomized to one of four groups for 8 weeks: placebo, pregabalin 150, 300, and $450 \mathrm{mg} /$ day. The primary endpoint was the comparison of end point mean pain scores, derived from daily diary ratings of pain intensity, among each of the pregabalin groups and the placebo group. Pregabalin $450 \mathrm{mg} /$ day significantly reduced the average severity of pain in the primary analysis compared with placebo $(-0.93$ on a $0-10$ scale; $p \leq 0.001)$, and significantly more patients in this group had $\geq 50 \%$ improvement in pain at the end point ( 29 vs. $13 \%$ in the placebo group; $p=0.003$; Crofford et al., 2005).

In the FREEDOM study performed by Crofford et al. (2008) pregabalin's efficacy of durability was assessed in a multicenter, double-blinded, placebo-controlled, 32-week trial. The trial included a 6 -week open-label phase followed by a 26-week double-blinded phase. During open-label weeks 1-3, patients received escalating doses of pregabalin to determine their optimal doses. During open-label weeks 4-6, patients received their optimal fixed doses (i.e., 300, 450, $600 \mathrm{mg} /$ day). Two hundred eighty-seven patients were randomized to placebo, and 279 patients were randomized to pregabalin. The primary endpoint was time to loss of therapeutic response (LTR), defined as $<30 \%$ reduction in pain or worsening of FM. Time to LTR was longer for pregabalin compared with placebo $(p<0.0001)$. Kaplan-Meier estimates of time-to-event showed half the placebo group had LTR by day 19; half the pregabalin group still had not lost response by trial end. One hundred seventy-four (61\%) placebo patients met LTR criteria compared with $90(32 \%)$ pregabalin patients at the end of the double-blinded phase (Crofford et al., 2008).

Mease et al. (2008) conducted a study which examined the efficacy of pregabalin for symptomatic pain relief and for the management of FM. It was a multicenter, double-blinded, placebocontrolled trial in which $748 \mathrm{FM}$ patients were randomized to placebo, pregabalin 300,450 , or $600 \mathrm{mg}$ /day for 13 weeks. The primary endpoint for symptomatic pain relief was comparison of mean pain scores among each pregabalin group and placebo. The primary endpoint for management of FM included mean pain scores, PGI-C score, and FIQ total score. Patients in all pregabalin groups demonstrated statistically significant improvement in mean pain score and in PGI-C score compared with placebo. Improvements in FIQ total score were numerically but not significantly greater than those for placebo (Mease et al., 2008).

Arnold et al. (2008) conducted an RCT which analyzed the effectiveness of pregabalin monotherapy in patients with FM. After 1 week of single-blinded placebo therapy, 750 patients were randomized to placebo, pregabalin 300, 450, or $600 \mathrm{mg}$ /day for 14 weeks The primary endpoint was comparison of mean pain scores, derived from daily diary ratings of pain intensity on a 0-10 scale, among each of the pregabalin groups and placebo. If positive, additional primary endpoints included the PGI-C score and the FIQ total score. Compared with placebo-treated subjects, mean changes in pain scores in pregabalin-treated subjects were significantly greater $(p<0.001: 300 \mathrm{mg} /$ day, $-0.71 ; 450 \mathrm{mg} /$ day, $-0.98 ; 600 \mathrm{mg} / \mathrm{day},-1.00)$. Compared with placebo, significantly more pregabalin-treated subjects reported improvement in PGI-C score ( $p<0.01$ for all three doses) and significant improvements in FIQ total score for the 450-mg/day $(p=0.004)$ and 600-mg/day $(p=0.003)$ doses (Arnold et al., 2008).

Finally, Straube et al. (2010) performed a meta-analysis of five pregabalin trials $(n=3,808)$ in FM utilizing company trial reports. Significant benefit of pregabalin over placebo was seen for a variety of endpoints including mean pain and sleep scores, the proportion of patients achieving at least $50 \%$ pain reduction, and most of the individual domains of short form 36.

The meta-analysis demonstrated that pregabalin-treated patients ( $\geq 300 \mathrm{mg} /$ day) experienced more somnolence, dizziness, $>7 \%$ weight gain, and discontinuations due to adverse events compared with placebo-treated patients. For dizziness and discontinuation due to adverse events there was a significant dose-response relationship. For somnolence, nausea, and weight gain there was no significant dose dependence. There was no significant difference between pregabalin and placebo in the rate of SAEs (approximately $2 \%$ in each case; Straube et al., 2010).

As of yet, there have not been any direct head-to-head comparisons of the three FDA approved drugs for FM. Häuser et al. (2010), however, recently compiled data from 11 RCTs enrolling 6,388 patients, which indirectly compared the benefits and harms of duloxetine, milnacipran, and pregabalin specifically in FM. The endpoints analyzed were reductions in pain, fatigue, sleep disturbance, depressed mood, HRQOL, and adverse events. They found that all three drugs were superior to placebo except for the following symptom-types: duloxetine for fatigue, milnacipran for sleep disturbances, and pregabalin for depressed mood. Häuser et al. (2010) 
found the pooled NNTs for a $30 \%$ pain reduction to be as follows: duloxetine 7.2, milnacipran 19, and pregabalin 8.6. The authors showed that there was no significant difference among the three drugs in achieving a minimum $30 \%$ reduction in pain and discontinuation rates due to adverse events were similar (Häuser et al., 2010). There were substantial differences in symptom-type alleviated and adverse effects produced for each particular drug. Duloxetine and pregabalin were superior to milnacipran for pain and sleep disturbance. Duloxetine was superior to milnacipran and pregabalin for depressed mood. Milnacipran and pregabalin were superior to duloxetine for fatigue. The risk of headache and nausea was higher with duloxetine and milnacipran compared with pregabalin. The risk of diarrhea was higher with duloxetine compared with milnacipran and pregabalin. The most frequent adverse effects noted in pregabalin-treated patients were weight gain and peripheral edema. Rare but SAEs reported were liver failure and suicidality for duloxetine and milnacipran, and heart failure for pregabalin. Häuser et al. (2010) found the numbers needed to harm (NNHs) for discontinuation due to adverse effects to be as follows: duloxetine 14.9, milnacipran 7.6, and pregabalin 7.6.

Gabapentin is another alpha-2-delta ligand and antiepileptic drug structurally similar to pregabalin, but not approved for the treatment of FM. Its usual half-life is $5-7 \mathrm{~h}$ in normal renal function. Gabapentin is almost entirely eliminated renally as the parent compound as a result of negligible metabolism and requires renal dosing (Smith and Barkin, 2010). Despite not being approved, this agent has shown potential benefit in clinical trials. Arnold et al. (2007) performed a randomized, double-blinded, placebo-controlled trial examining the effectiveness/safety of gabapentin in treating FM. Patients were randomized to either gabapentin 1,200-2,400 mg/day $(n=75)$ or placebo $(n=75)$ for 12 weeks. The primary endpoint was the BPI average pain severity score. The authors concluded that gabapentin 1,200-2,400 mg/day is safe and efficacious for the treatment of pain and other symptoms associated with FM (Arnold et al., 2007).

Gamma-hydroxybutyrate (also known as sodium oxybate), a precursor of GABA known to possess strong sedative qualities, has been shown to improve fatigue, pain, and sleep architecture in FM (Scharf et al., 2003). Russell et al. (2009) randomized 118 patients with FM (92 of which completed the study) after discontinuing their pre-study FM medications to receive 4.5 or $6.0 \mathrm{~g}$ of sodium oxybate or placebo once per night for 8 weeks. The primary endpoint was a composite score in three co-primary selfreported measures: patient's pain rating (in daily electronic dairies) on a visual analog scale, the FIQ score, and the PGI-C score. Significant benefit was observed with both doses of sodium oxybate with regards to changes in the primary endpoint and subjective sleep quality. Improvements in patient pain ratings correlated well with sleep outcomes. Sodium oxybate was well-tolerated overall, with dose-related nausea ( $\leq 28 \%$ of patients) and dizziness $(\leq 18 \%$ of patients) resolving with continued therapy (Russell et al., 2009).

Though speculative, it is conceivable that agents such as pramipexole and tizanidine may possess beneficial effects for patients with FM and co-existing restless leg syndrome or spasticity, respectively. Pramipexole is a dopamine agonist utilized for Parkinson's disease that is also useful for the treatment of restless leg syndrome (Bennett, 2001). Pramipexole may improve both pain and sleep in
FM patients (Holman and Myers, 2005). Tizanidine is a centrally acting alpha-2-adrenergic agonist that may possess muscle-relaxing effects in patients with spasticity. Tizanidine potentially may provide benefit for FM patients by reductions in pain, improvement in sleep, and improvement in QOL measures (Russell et al., 2002). Furthermore, tizanidine treatment reduced substance P levels in the CSF of FM patients.

Tramadol is a compound that possesses weak analgesic effects by binding to mu-opioid receptors, but its major pain-relieving effects are through serotonin-norepinephrine reuptake inhibition. The activity of the drug is focused on the M1 metabolite (O-desmethyltramadol), which yields six times more potent analgesia than the parent compound. The usual half-life of tramadol is 8 and $9 \mathrm{~h}$ for the M1 metabolite. It is metabolized by CYP450 enzymes 2B6, 2D6, and 3A4 (Smith and Barkin, 2010). Tramadol seems to be beneficial for the treatment of FM both alone and as a fixed-dose combination with acetaminophen (Russell et al., 2000; Bennett, 2001; Bennett et al., 2003).

Tapentadol is an agent that has not yet been studied for the treatment of FM. It does, however, possess some opioid effects as well as inhibits the reuptake of norepinephrine. Tapentadol exhibits extensive hepatic first pass effects, and its metabolism is largely hepatic primarily by the Phase II pathway (85\%; glucuronidation, conjugation) and minor (15\%) Phase I CYP450 oxidation (2C9), 2C19 (13\%), 2D6 (2\%). Thus there is minimal risk of any CYP450 drug interactions (Smith and Barkin, 2010). Nonanalgesic $\mathrm{N}$-desmethyl and $\mathrm{OH}$-tapentadol metabolites follow with metabolism by conjugation (Smith and Barkin, 2010). Phase II metabolism is a high-capacity/low-affinity system providing water soluble, inactive metabolites for renal elimination. Tapentadol is 99\% renally excreted: $70 \%$ as inactive metabolites and only $3 \%$ as the parent compound. It has a plasma protein binding of $20 \%$ and thus no significant plasma protein-binding interactions (Smith and Barkin, 2010).

Ultimately the management of FM can be approached in a stepwise manner, utilizing the most tried and true strategies initially and resorting to less well-studied agents with potential side effects based on individual patient responsiveness. This may be illustrated by a potential speculative schematic which represents a "step-ladder" type approach to the clinical management of FM (Smith and Barkin, 2010; Figure 4).

\section{CONCLUSION}

Fibromyalgia is a disorder characterized by CWP as well as other somatic symptoms. It appears to impart marked morbidity, negatively impacting physical functioning, HRQOL, sleep, emotional health, and social well-being, thus requiring prompt diagnosis and treatment. Non-FDA approved agents, such as amitriptyline and cyclobenzaprine, have been utilized in the "off-label" management of FM. There is evidence to support the short-term use of amitriptyline $25 \mathrm{mg}$ /day, but higher doses for longer periods do not appear to be efficacious (Nishishinya et al., 2008). Cyclobenzaprine, which is structurally similar to amitriptyline, seems to be effective for the musculoskeletal component and improves sleep (Goldenberg, 1989). Agents such as SSRIs (Otto et al., 2008) and opioids appear to demonstrate little efficacy in FM. The three FDA approved agents, pregabalin, duloxetine, and 


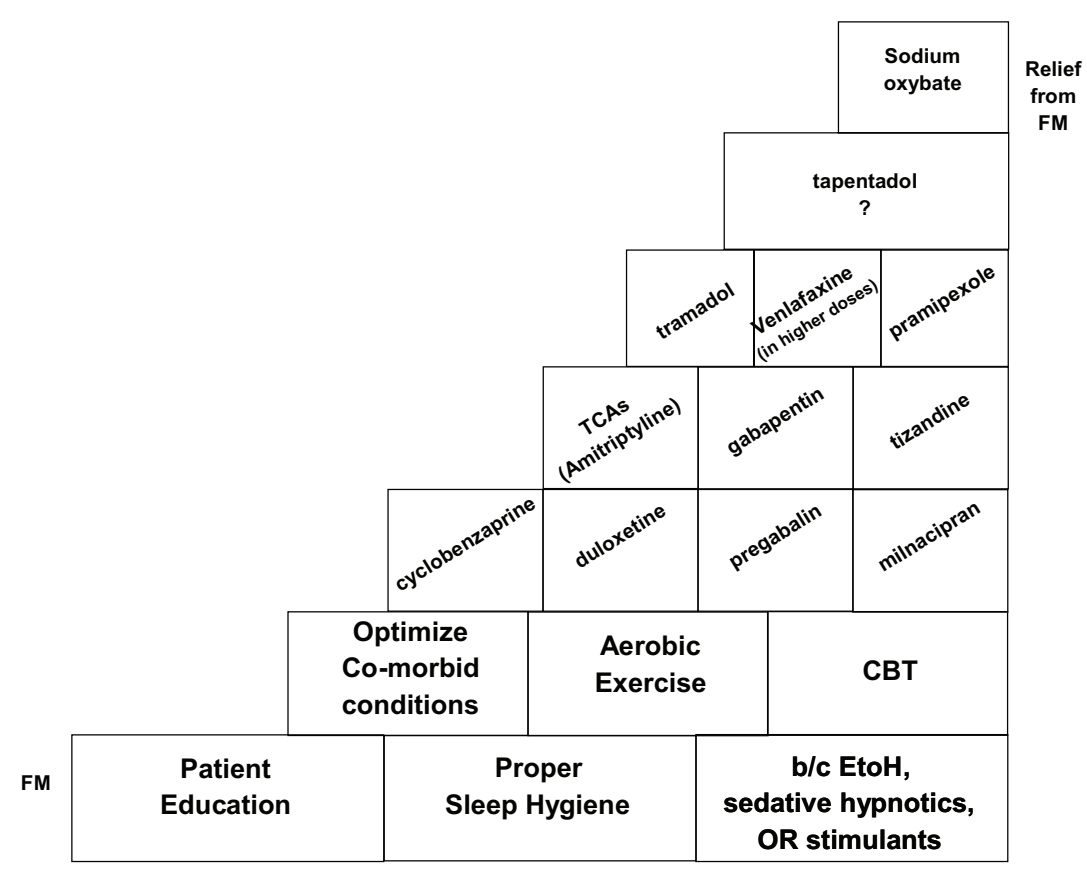

FIGURE 4 | Clinical algorithm for the management of fibromyalgia.

milnacipran, were shown to be superior to placebo except for the following symptom-types: duloxetine for fatigue, milnacipran for sleep disturbances, and pregabalin for depressed mood (Häuser et al., 2010). Other centrally acting agents may also show benefit in FM patients with a predominant symptom-type. For example, gamma-hydroxybutyrate, with its strong sedative qualities, may be clinically useful for FM patients with insomnia/sleep disturbance (Scharf et al., 2003; Russell et al., 2009). Pramipexole, a dopamine agonist used for Parkinson's disease, could be potentially useful for FM patients with concomitant restless leg syndrome (Bennett, 2001; Holman and Myers, 2005). Tramadol, which possesses some analgesic activity, may be utilized for FM patients with a significant pain component to their disease (Russell et al., 2000; Bennett,

\section{REFERENCES}

Affaitati, G., Costantini, R., Fabrizio, A., Lapenna, D., Tafuri, E., and Giamberardino, M. A. (2011). Effects of treatment of peripheral pain generators in fibromyalgia patients. Eur. J. Pain 15, 61-69.

Arnold, L. M., Clauw, D. J., Wohlreich, M. M., Wang, F., Ahl, J., Gaynor, P. J., and Chappell, A. S. (2009). Efficacy of duloxetine in patients with fibromyalgia: pooled analysis of 4 placebo-controlled clinical trials. Prim. Care Companion J. Clin. Psychiatry 11, 237-244.

Arnold, L. M., Gendreau, R. M., Palmer, R. H., Gendreau, J. F., and Wang, Y. (2010). Efficacy and safety of milnacipran $100 \mathrm{mg} /$ day in patients with fibromyalgia: results of a randomized, double-blind, placebo-controlled trial. Arthritis Rheum. 62, 2745-2756.
Arnold, L. M., Goldenberg, D. L., Stanford, S. B., Lalonde, J. K., Sandhu, H. S., Keck, P. E. Jr., Welge, J. A., Bishop, F., Stanford, K. E., Hess, E. V., and Hudson, J. I. (2007). Gabapentin in the treatment of fibromyalgia: a randomized, double-blind, placebocontrolled, multicenter trial. Arthritis Rheum. 56, 1336-1344.

Arnold, L. M., Lu, Y., Crofford, L. J., Wohlreich, M., Detke, M. J., Ivengat, S., and Goldstein, D. J. (2004). A double-blind, multicenter trial comparing duloxetine with placebo in the treatment of fibromyalgia patients with or without major depressive disorder. Arthritis Rheum. 50, 2974-2984.

Arnold, L. M., Rosen, A., Prichett, Y. L., D’Souza, D. N., Goldstein, D. J., Iyengar, S., and Wernicke, J. F. (2005). A randomized, double-

2001; Bennett et al., 2003). Tizanidine, an alpha-2-adrenergic agonist muscle relaxant, could be potentially used for FM patients with spasticity. Based on these observations, choice of treatment medication should be tailored to fit individual patient needs and preferences. Finally, there is growing evidence supporting the effectiveness of aerobic exercise, education, and CBT in the treatment of FM. They should be considered, along with other multi-modal interventions, for more frequent utilization in clinical practice (Williams, 2005; Chou et al., 2007).

\section{ACKNOWLEDGMENT}

The authors would like to acknowledge the efforts of Pya Seidner in the preparation of this manuscript.

blind, placebo-controlled trial of duloxetine in the treatment of women with fibromyalgia with or without major depressive disorder. Pain 119, 5-15.

Arnold, L. M., Russell, I. J., Diri, E. W., Duan, W. R., Young, J. P.Jr., Sharma, U., Martin, S. A., Barrett, J. A., and Haig, G. (2008). A 14-week, randomized, double-blinded, placebo-controlled monotherapy trial of pregabalin in patients with fibromyalgia. J. Pain 9, 792-805.

Barkin, R. L. (2008). Pregabalin: a critical review. Pain Med. Netw. 24, 8-9.

Bennett, R. (2005). The Fibromyalgia Impact Questionnaire (FIQ): a review of its development, current version, operating characteristics and uses. Clin. Exp. Rheumatol. 23, S154-S162.
Bennett, R. M. (2001). Pharmacologica treatment of fibromyalgia. J. Funct. Syndr. 1, 79-92.

Bennett, R. M., Friend, R., Jones, K. D., Ward, R., Han, B. K., and Ross, R. L. (2009a). The Revised Fibromyalgia Impact Questionnaire (FIQR): validation and psychometric properties. Arthritis Res. Ther.11, R120.

Bennett, R. M., Bushmakin, A. G., Cappelleri, J. C., Zlateva, G., and Sadosky, A. B. (2009b). Minimal clinically important difference in the fibromyalgia impact questionnaire. J. Rheumatol. 36, 1304-1311.

Bennett, R. M., Jones, J., Turk, D. C., Russell, I. J., and Matallana, L. (2007). An internet survey of 2,596 people with fibromyalgia. $B M C$ Musculoskelet. Disord. 8, 27. doi: 10.1186/1471-2474-8-27 
Bennett, R. M., Kamin, M., Mrim, R., and Rosenthal, N. (2003). Tramadol and acetaminophen combination tablets in the treatment of fibromyalgia pain: a double-blind, randomized, placebocontrolled study. Am. J. Med. 114, 537-545.

Bernard, A. L., Prince, A., and Edsall, P. (2000). Quality of life issues for fibromyalgia patients. Arthritis Care Res. 13, 42-50.

Bernardy, K., Füber, N., Köllner, V., and Häuse, W. (2010). Efficacy of cognitive-behavioral therapies in fibromyalgia syndrome - a systematic review and metaanalysis of randomized controlled trials. J. Rheumatol. 37, 1991-2005.

Blanco, I., Béritze, N., Argüelles, M., Cárcaba, V., Fernández, F. Janciauskiene, S., Oikonomopoulou, K., de Serres, F. J., Fernández-Bustillo, E., and Hollenberg, M. D. (2010). Abnormal overexpression of mastocytes in skin biopsies of fibromyalgia patients. Clin. Rheumatol. 29, 1403-1412.

Bradley, L. A., and Alarcón, G. S. (1999). Is Chiari malformation associated with increased levels of substance $\mathrm{P}$ and clinical symptoms in persons with fibromyalgia? Arthritis Rheum. 42, 2731-2732.

Bradley, L. A., Alberts, K. R., Alarcón, G. S., Alexander, M. T., Mount, J. M., Weigent, D. A., Liu, H. G., Blalock, J. E., Aaron, L. A., Alexander, R. W., San Pedro, E. C., Martin, M.Y., and Morell, A. C. (1996). Abnormal brain regional cerebral blood flow and cerebrospinal fluid levels of substance $P$ in patients and non-patients with fibromyalgia. Arthritis Rheum. 39, 1109.

Branco, J. C., Zahrisson, O., Perrot, S., Mainguy, Y.; Multinational Coordinator Study Group. (2010). A European multicenter randomized double-blind placebo-controlled monotherapy clinical trial of milnacipran in treatment of fibromyalgia. J. Rheumatol. 37, 851-859.

Burgmer, M., Pogatzki-Zahn, E., Gaubitz, M., Wessoleck, E., Heuft, G., and Pfleiderer, B. (2009). Altered brain activity during pain processing in fibromyalgia. Neuroimage 44, 502-508.

Busch, A. J., Schachter, C. L., Overend, T. J., Peloso, P.M., and Barber, K.A. (2008). Exercise for fibromyalgia: a systematic review. J. Rheumatol. 35, 1130-1144.

Carville, S. F., Arendt-Nielsen, S., Bliddal, H., Blotman, F., Branco, J. C., Buskila, D., Da Silva, J. A., Danneskiold-Samsøe, B., Dincer, F., Henriksson, C., Henriksson, K. G., Kosek, E., Longley, K., McCarthy, G. M., Perrot, S., Puszczewicz, M., SarziPuttini, P., Silman, A., Späth, M., Choy, E. H.; EULAR. (2008). EULAR evidence-based recommendations for the management of fibromyalgia syndrome.Ann. Rheum. Dis. 67, 536-541.

Chappell, A. S., Littlejohn, G., Kajdasz, D. K., Scheinberg, M., D’Souza, D. N., and Moldofsky, H. (2009a). A 1-year safety and efficacy study of duloxetine in patients with fibromyalgia. Clin. J. Pain 25, 365-375.

Chappell, A. S., Bradley, L. A., Wiltse, C., Detke, M. J., D'Souza, D. N., and Spaeth, M. (2009b). A six-month double-blind, placebo-controlled, randomized clinical trial of duloxetine for the treatment of fibromyalgia. Int . J. Gen. Med. 1, 91-102.

Chou, R., Huffman, L. H.; American Pain Society; American College of Physicians. (2007). Nonpharmacologic therapies for acute and chronic low back pain: a review of the evidence for an American Pain Society/American College of Physicians clinical practice guideline. Ann. Intern. Med. 147, 492-504.

Choy, E. H., Mease, P. J., Kajdasz, D. K., Wohlreich, M. M., Crits-Christoph, P., Walker, D. J., and Chappell, A. S. (2009). Safety and tolerability of duloxetine in the treatment of patients with fibromyalgia: pooled analysis of data from five clinical trials. Clin. Rheumatol. 28, 1035-1044.

Clauw, D. J., Mease, P., Palmer, R. H., Gendreau, R. M., and Wang, Y. (2008). Milnacipran for the treatment of fibromyalgia in adults: a 15-week, multicenter, randomized, double-blind, placebo-controlled, multiple-dose clinical trial. Clin. Ther. 30, 1988-2004.

Clauw, D. J., Schmidt, M., Radulovic, D., Singer, A., Katz, P., and Bresette, J. (1997). The relationship between fibromyalgia and interstitial cystitis. J. Psychiatr. Res. 31, 125-131.

Coaccioli, S., Varrassi, G., Sabatini, C., Marinangeli, F., Giuliani, M., and Puxeddu, A. (2008). Fibromyalgia: nosography and therapeutic perspectives. Pain Pract. 8, 190-201.

Cordero, M. D., Moreno-Fernández, A. M., Carmona-López, M. I., SánchezAlcázar, J. A., Rodríguez, A. F., Navas, P., and de Miguel, M. (2010). Mitochondrial dysfunction in skin biopsies and blood mononuclear cells from two cases of fibromyalgia patients. Clin.Biochem. 43, 1174-1176.

Crofford, L. J., Mease, P. J., Simpson, S. L., Young, J. P. Jr., Martin, S. A., Haig, G. M., and Sharma, U. (2008). Fibromyalgia relapse evaluation and efficacy for durability of meaningful relief (FREEDOM): a 6-month, double-blind, placebo-controlled trial with pregabalin. Pain 136, 419-431.

Crofford, L. J., Rowbotham, M. C., Mease, P. J., Russell, I. J., Dworkin,
R. H., Corbin, A. E., Young, J. P. Jr., LaMoreaux, L. K., Martin, S. A., Sharma, U.; Pregabalin 1008-105 Study Group. (2005). Pregabalin for the treatment of fibromyalgia syndrome: results of a randomized, double-blind, placebo-controlled trial Arthritis Rheum. 52, 1264-1273.

Curran, M. P. (2009). Duloxetine: in patients with fibromyalgia. Drugs 69, 1217-1227.

de Souza, J. B., Potvin, S., Goffaux, P. Charest, J., and Marchand, S. (2009). The deficit of pain inhibition in fibromyalgia is more pronounced in patients with comorbid depressive symptoms. Clin. J. Pain 25, 123-127.

Desmeules, J. A., Cedraschi, C., Rapiti, E., Baumgartner, E., Finckh, A., Cohen, P., Dayer, P., and Vischer, T. L. (2003). Neurophysiologic evidence for a central sensitization in patients with fibromyalgia. Arthritis Rheum. 48, 1420-1429.

Di Piero, V., Jones, A. K., Iannotti, F., Powell, M., Perani, D., Lenzi, G. L. and Frackowiak, R. S. (1991). Chronic pain: a PET study of the central effects of percutaneous high cervical cordotomy. Pain 46, 9-12.

Diers, M., Schley, M. T., Rance, M., Yilmaz, P., Lauer, L., Rukwied, R., Schmelz, M. and Flor, H. (2011). Differential central pain processing following repetitive intramuscular proton/prostaglandin $\mathrm{E}(2)$ injections in female fibromyalgia patients and healthy controls. Eur. J. Pain (in press).

Figueroa, A., Kingsley, J. D., McMillan, V., and Panton, L. B. (2008). Resistance exercise training improves heart rate variability in women with fibromyalgia. Clin. Physiol. Funct. Imaging 28, 49-54.

Fishbain, D.A., Cutler, R., Rosomoff, H.L. and Rosomoff, R. S. (2000). Evidencebased data from animal and human experimental studies on pain relief with antidepressants: a structured review. Pain Med. 1, 310-316.

Geisser, M. E., Gracely, R. H., Giesecke, T., Petzke, F. W., Williams, D. A., and Clauw, D. J. (2007). The association between experimental and clinical pain measures among persons with fibromyalgia and chronic fatigue syndrome. Eur. J. Pain 11, 202-207.

Geisser,M.E., Palmer, R.H., Gendreau, R. M., Wang, Y., and Clauw, D. J. (2011) A pooled analysis of two randomized, double-blind, placebo-controlled trials of milnacipran monotherapy in the treatment of fibromyalgia. Pain Pract. 11, 120-131.

Gendreau, R. M., Thorn, M.D., Gendreau, J. F., Kranzler, J. D., Ribeiro, S., Gracely, R. H., Williams, D. A., Mease, P. J., McLean, S. A., and Clauw, D. J. (2005). Efficacy of milnacipran in patients with fibromyalgia. J. Rheumatol. 32, 1975-1985.

Gerster, J. C., and Hadj-Djilani, A. (1984). Hearing and vestibular abnormalities in primary fibrositis syndrome. $J$. Rheumatol. 11, 678-680.

Giesecke, J., Reed, B. D., Haefner, H. K., Giesecke, T., Clauw, D. J., and Gracely, R. H. (2004). Quantitative sensory testing in vulvodynia patients and increased peripheral pressure pain sensitivity. Obstet. Gynecol. 104, 126-133.

Giesecke, T., Gracely, R. H., Williams, D. A., Geisser, M. E., Petzke, F. W., and Clauw, D. J. (2005). The relationship between depression, clinical pain, and experimental pain in a chronic pain cohort. Arthritis Rheum. 52, 1577-1584.

Goldenberg, D. L. (1989). Treatment of fibromyalgia syndrome. Rheum. Dis. Clin. North Am. 15, 61-71.

Goldenberg, D. L., Clauw, D. J., Palmer, R. H., Mease, P., Chen, W., and Gendreau, R. M. (2010). Durability of therapeutic response to milnacipran treatment for fibromyalgia. Results of a randomized, double-blind, monotherapy 6-month extension study. Pain Med. 11, 180-194.

Gracely, R. H., Petzke, F., Wolf, J. M., and Clauw, D. J. (2002). Functional magnetic resonance imaging evidence of augmented pain processing in fibromyalgia. Arthritis Rheum. 46, 1333-1343.

Gürsoy, S., Erdal, E., Herken, H., Madenci, E., Alaşehirli, B., and Erdal, N. (2003). Significance of catechol-O-methyltransferase gene polymorphism in fibromyalgia syndrome. Rheumatol. Int. 23, 104-107.

Hassett, A. L., and Gevirtz, R. N. (2009). Nonpharmacologic treatment for fibromyalgia: patient education, cognitive-behavioral therapy, relaxation techniques, and complementary and alternative medicine. Rheum.Dis. Clin. North Am. 35, 393-407.

Häuser, W., Petzke, F., and Sommer, C. (2010). Comparative efficacy and harms of duloxetine, milnacipran, and pregabalin in fibromyalgia syndrome. J. Pain 11, 505-521.

Holman, A. J., and Myers, R. R. (2005). A randomized, double-blind, placebocontrolled trial of pramipexole, a dopamine agonist, in patients with fibromyalgia receiving concomitant medications. Arthritis Rheum. 52, 2495-2505.

Hsieh, J. C., Stahle-Backdahl, M., Hagermark, O., Stone-Elander, S., Rosenquist, G., and Ingvar, M. (1996). Traumatic nociceptive pain activates the hypothalamus and the periaqueductal gray: a positron emission tomography study. Pain 64, 303-314. 
Jones, J., Rutledge, D. N., Jones, K. D., Matallana, L., and Rooks, D. S. (2008). Self-assessed physical function levels of women with fibromyalgia: a national survey. Womens Health Issues $18,406-412$.

Jones, K. D., Burckhardt, C. S., Clark, S. R., Bennett, R. M., and Potempa, K. M. (2002). A randomized controlled trial of muscle strengthening versus flexibility training in fibromyalgia. $J$. Rheumatol. 29, 1041-1048.

Jones, K. D., and Liptan, G. L. (2009). Exercise interventions in fibromyalgia: clinical applications from the evidence. Rheum. Dis. Clin. North Am. 35, 373-391.

Kim, S. H., Kim, D. H., Oh, D. H., and Claud, D. J. (2008). Characteristic electron microscopic findings in the skin of patients with fibromyalgia preliminary study. Clin. Rheumatol. 27, 407-411.

Langemark, M., Jensen, K., Jensen, T. S., and Olesen, J. (1989). Pressure pain thresholds and thermal nociceptive thresholds in chronic tension-type headache. Pain 38, 203-210.

Lui, Z., Welin, M., Bragee, B., and Nyberg, F. (2000). A high-recovery extraction procedure for quantitative analysis of substance $\mathrm{P}$ and opioid peptides in human cerebropinal fluid. Peptides 21, 853-860.

Maixner, W., Fillingim, R., Booker, D., and Sigurdsson, A. (1995). Sensitivity of patients with painful temporomandibular disorders to experimentally evoked pain. Pain 63, 341-351.

Mease, P. J., Clauw, D. J., Gendreau, R. M., Rao, S. G., Kranzler, J., Chen, W., and Palmer, R. H. (2009). The efficacy and safety of milnacipran for treatment of fibromyalgia. a randomized, doubleblind, placebo-controlled trial. $J$. Rheumatol. 36, 398-409.

Mease, P. J., Russell, I. J., Arnold, L. M., Florian, H., Young, J. P. Jr., Martin, S. A., and Sharma, U. (2008). A randomized, double-blind, placebo-controlled, phase III trial of pregabalin in the treatment of patients with fibromyalgia. J. Rheumatol. 35, 502-514.

Miedema, H. S., van der Linden, S. M., Rasker, J. J., and Valkenburg, H. A. (1998). National database of patients visiting rheumatologists in The Netherlands: the standard diagnosis register of rheumatic diseases. A report and preliminary analysis. $\mathrm{Br}$. J. Rheumatol. 37, 555-561.

Ness, T. J., Powell-Boone, T., Cannon, R., Lloyd, L. K., and Fillingim, R. B. (2005). Psychophysical evidence of hypersensitivity in subjects with interstitial cystitis. J. Urol. 173, 1983-1987.

Nishishinya, B., Urrútia, G., Walitt, B., Rodriguez, A., Bonfill, X., Alegre, C., and Darko, G. (2008). Amitriptyline in the treatment of fibromyalgia: a systematic review of its efficacy. Rheumatology (Oxford) 47, 1741-1746. Normand, E., Potvin, S., Gaumond, I., Cloutier, G., Corbin, J. F., and Marchand, S. (2011). Pain inhibition is deficient in chronic widespread pain but normal in major depressive disorder. J. Clin. Psychiatry 72, 219-224.

Otto, M., Bach, F. W., Jensen, T. S., Brøsen, K., and Sindrup, S. H. (2008). Escitalopram in painful polyneuropathy: a randomized, placebo-controlled, cross-over trial. Pain 139, 275-283. Pattany, P. M., Yezierski, R. P., WiderstromNoga, E. G., Bowen, B. C., MartinezArizala, A., Garcia, B. R., and Quencer, R. M. (2002). Proton magnetic resonance spectroscopy of the thalamus in patients with chronic neuropathic pain after spinal cord injury. AJNR Am. J. Neuroradiol. 23, 901-905.

Rodrigues, A. C., Nicholas, V. G., Schmidt, S., and Mauderli, A. P. (2005). Hypersensitivity to cutaneous thermal nociceptive stimuli in irritable bowel syndrome. Pain 115, 5-11.

Rooks, D. S., Gautam, S., Romeling, M., Cross, M. L., Stratigakis, D., Evans, B., Goldernberg, D. L., Iverson, M. D., and Katz,J. N. (2007). Group exercise, education, and combination self-management in women with fibromyalgia: a randomized trial. Arch. Intern. Med. 167, 2192-2200.

Russell, I. J., Kamin, M., Bennett, R. M., Schnitzer, T. J., Gren, J. A., and Katz, W. A. (2000). Efficacy of tramodol in treatment of pain in fibromylagia. J. Clin. Rheumatol. 6, 250-257.

Russell, I. J., Mease, P. J., Smith, T. R., Kajdasz, D. K., Wohlreich, M. M., Detke, M. J., Walker, D. J., Chappell, A. S., and Arnold, L. M. (2008). Efficacy and safety of duloxetine for treatment of fibromyalgia in patients with or without major depressive disorder: results from a 6-month, randomized, double-blind, placebo-controlled, fixed-dose trial. Pain 136, 432-444.

Russell, I. J., Michalek, J. E., Xiao, Y., Haynes, W., Vertiz, R., and Lawrence, R. A. (2002). Therapy with a central alpha 2-adrenergic agonist (tizanidine) decreases cerebrospinal fluid substance $\mathrm{P}$, and may reduce serum hyaluronic acid as it improves the clinical symptoms of the fibromyalgia syndrome. Arthritis Rheum. 46, S614.

Russell,I.J.,Orr,M.D.,Littman,B.,Vipraio, G. A., Alboukrek, D., Michalek, J. E., Lopez, Y., and MacKillip, F. (1994). Elevated cerebrospinal fluid levels of substance $P$ in patients with the fibromyalgia syndrome. Arthritis Rheum. 37, 1593-1601.

Russell, I. J., Perkins, A. T., Michalek, J. E., and Oxybate SXB-26 Fibromyalgia Syndrome Study Group. (2009).
Sodium oxybate relieves pain and improves function in fibromyalgia syndrome: a randomized, doubleblind, placebo-controlled, multicenter clinical trial. Arthritis Rheum. 60, 299-309.

Russell, I. J., Vaeroy, H., Javors, M., and Nyberg, F. (1992). Cerebrospinal fluid biogenic amine metabolites in fibromyalgia/fibrositis syndrome and rheumatoid arthritis. Arthritis Rheum. 35, 550-556.

Sarchielli, P., Di Filippo, M., Nardi, K., and Calabresi, P. (2007a). Sensitization, glutamate, and the link between migraine and fibromyalgia. Curr. Pain Headache Rep. 11, 343-351.

Sarchielli, P., Mancini, M. L., Floridi, A., Coppola, F., Rossi, C., Nardi, K., Acciarresi, M., Pini, L. A., and Calabresi, P. (2007b). Increased levels of neurotrophins are not specific for chronic migraine: evidence from primary fibromyalgia syndrome. J. Pain $8,737-745$.

Sayar, K., Aksu, G., Ak, I., and Tosun, M. (2003). Venlafaxine treatment of fibromyalgia. Ann. Pharmacother. 37, 1561-1565.

Scharf, M. B., Baumann, M., and Berkowitz, D. V. (2003). The effects of sodium oxybate on clinical symptoms and sleep patterns in patients with fibromyalgia. J. Rhematol. 30 , 1070-1074.

Smith, H. S. (2009). The Pathophysiology of Fibromyalgia as part of National Lecture Series. Baltimore: John Hopkins Medical Institute.

Smith, H. S., and Barkin, R. L. (2010). Fibromyalgia syndrome: a discussion of the syndrome and pharmacotherapy. Am. J. Ther. 17, 418-439.

Smith, H. S., Harris, R. E., and Claue, D. J. (2011). Fibromyalgia: an afferent processing disorder leading to a complex pain generalized syndrome. Pain Physician (in press)

Stahl, S. M., Grady, M. M., Moret, C., and Briley, M. (2005). SNRIs: their pharmacology, clinical efficacy, and tolerability in comparison with other classes of antidepressants. CNS Spectr. 10, 732-747.

Staud, R. (2010). Is it all central sensitization? Role of peripheral tissue nociception in chronic musculoskeletal pain Curr. Rheumatol. Rep. 12, 448-454.

Staud, R., Bovee, C. E., Robinson, M. E., and Price, D. D. (2008a). Cutaneous C-fiber pain abnormalities of fibromyalgia patients are specifically related to temporal summation. Pain 139, 315-323.

Staud, R., Craggs, J. G., Perlstein, W. M., Robinson, M. E., and Price, D. D. (2008b). Brain activity associated with slow temporal summation of C-fiber evoked pain in fibromyalgia patients and healthy controls. Eur. J. Pain 12, 1078-1089.

Staud, R., Cannon, R. C., Mauderli, A. P., Robinson, M. E., Price, D. D., and Vierck, C. J. Jr. (2003a). Temporal summation of pain from mechanical stimulation of muscle tissue in normal controls and subjects with fibromyalgia syndrome. Pain 102, 87-95.

Staud, R., Robinson, M. E., Vierck, C. J. Jr., Cannon, R. C., Mauderli, A. P., and Price, D. D. (2003b). Ratings of experimental pain and pain-related negative affect predict clinical pain in patients with fibromyalgia syndrome. Pain 105, 215-222.

Staud, R., Robinson, M. E., Vierck, C. J. Jr., and Price, D. D. (2003c). Diffuse noxious inhibitory controls (DNIC) attenuate temporal summation of second pain in normal males but not in normal females or fibromyalgia patients. Pain 101, 167-174.

Staud, R., Nagel, S., Robinson, M. E., and Price, D. D. (2009). Enhanced central pain processing of fibromyalgia patients is maintained by muscle afferent input: a randomized, doubleblind, placebo-controlled study. Pain 145, 96-104.

Staud, R., Price, D. D., Robinson, M. E., Mauderli, A. P., and Vierck, C. J. (2004). Maintenance of windup of second pain requires less frequent stimulation in fibromyalgia patients compared to normal controls. Pain 110, 689-696

Staud, R., Robinson, M. E., and Price, D. D. (2007). Temporal summation of second pain and its maintenance are useful for characterizing widespread central sensitization of fibromyalgia patients. J. Pain 8, 893-901.

Staud, R., Vierck, C. J., Cannon, R. L., Mauderli, A. P., and Price, D. D. (2001). Abnormal sensitization and temporal summation of second pain (wind-up) in patients with fibromyalgia syndrome. Pain 91, 165-175.

Straube, S., Derry, S., Moore, R. A., and McQuay, H. J. (2010). Pregabalin in fibromyalgia: meta-analysis of efficacy and safety from company clinical trial reports. Rheumatology (Oxford) 49, 706-715.

Thieme, K., Flor, H., and Turk, D. (2006) Psychological pain treatment in fibromyalgia syndrome: efficacy of operant behavioural and cognitive behavioural treatments. Arthritis Res. Ther. 8, 121-132.

Thieme, K., and Gracely, R. H. (2009). Are psychological treatments effective for fibromyalgia pain? Curr. Rheumatol. Rep. 11, 443-450.

Thomas, E. N., and Blotman, F. (2010). Aerobic exercise in fibromyalgia: a practical review. Rheumatol. Int. 30, 1143-1150. 
Tofferi, J. K., Jackson, J. L., and O'Malley, P. G. (2004). Treatment of fibromyalgia with cyclobenzaprine: a meta-analysis. Arthritis Rheum. 51, 9-13.

Uçeyler, N., Häuser, W., and Sommer, C. (2008). A systematic review on the effectiveness of treatment with antidepressants in fibromyalgia syndrome. Arthritis Rheum. 59, 1279-1298.

Uçeyler, N., Valenza, R., Stock, M., Schedel, R., Sprotte, G., and Sommer, C. (2006). Reduced levels of antiinflammatory cytokines in patients with chronic widespread pain. Arthritis Rheum. 54, 2656-2664.

Vaerøy, H., Helle, R., Førre, O., Kåss, E., and Terenius, L. (1988). Elevated CSF levels of substance $\mathrm{P}$ and high incidence of Raynaud phenomenon in patients with fibromyalgia: new features for diagnosis. Pain 32, 21-26.

Valkeinen, H., Alen, M., Hakkinen, A., Hannonen, P., Kukkonen-Harjula, K., and Häkkinen, K. (2008). Effects of concurrent strength and endurance training on physical fitness and symptoms in postmenopausal women with fibromyalgia: a randomized controlled trial. Arch. Phys. Med. Rehabil. 89, 1660-1666.

Vitton, O., Gendreau, M., Gendreau, J., Kranzler, J., and Rao, S. G. (2004). A double-blind placebo-controlled trial of milnacipran in the treatment of fibromyalgia. Hum. Psychopharmacol. 19, S27-S35.

Wang, H., Moser, M., Schiltenwolf, M., and Buchner, M. (2008). Circulating cytokine levels compared to pain in patients with fibromyalgia - a prospective longitudinal study over 6 months. J. Rheumatol. 35, 1366-1370.

Wilke, W. S. (2009). New developments in the diagnosis of fibromyalgia syndrome: say goodbye to tender points? Cleve. Clin. J. Med. 76, 345-352.

Williams, D. A. (2005). "Cognitive and behavioral approaches to chronic pain," in Fibromyalgia and Other Control Pain Syndromes, eds D. J. Wallace and D. J. Clauw (Philadelphia, PA: Lippincott Williams \& Wilkins), 343-352.

Wolfe, F. (2003). Pain extent and diagnosis: development and validation of the regional pain scale in 12,799 patients with rheumatic disease. $J$. Rheumatolol. 30, 369-378.

Wolfe, F. (2010). New American College of Rheumatology criteria for fibromyalgia: a twenty-year journey. Arthritis Care Res. (Hoboken) 62, 583-584.

Wolfe, F., Clauw, D. J., Fitzcharles, M. A., Goldenberg, D. L., Katz, R. S., Mease, P., Russell, A. S., Russell, I. J., Winfield, J. B., and Yunus, M. B. (2010). The American College of Rheumatology preliminary diagnostic criteria for fibromyalgia and measurement of symptom severity. Arthritis Care Res. (Hoboken) 62, 600-610.

Wolfe, F., Ross, K., Anderson, J., Russell, I. J., and Hebert, L. (1995). The prevalence and characteristics of fibromyalgia in the general population. Arthritis Rheum. 38, 19-28.
Wood, P. B., Patterson, J. C. II, Sunderland J. J., Tainter, K. H., Glabus, M. F., and Lilien, D. L. (2007). Reduced presynaptic dopamine activity in fibromyalgia syndrome demonstrated with positron emission tomography: a pilot study. J. Pain 8, 51-58.

Woolf, C. J. (2011). Central sensitization: implications for the diagnosis and treatment of pain. Pain 152, s2-s15.

Xu, X. J., Dalsgaard, C. J., and WiesenfeldHallin, Z. (1992). Spinal substance $P$ and N-methyl-D-aspartate receptors are coactivated in the induction of central sensitization of the nociceptive flexor reflex. Neuroscience 51,641-648.

Yarnitsky, D. (2010). Conditioned pain modulation (the diffuse noxious inhibitory control-like effect): its relevance for acute and chronic pain states. Curr. Opin. Anaesthesiol. 23, 611-615.

Yarnitsky, D., Arendt-Nielsen, L. Bouhassira, D., Edwards, R. R., Fillingim, R. B., Granot, M., Hansson, P., Lautenbacher, S., Marchand, S., and Wilder-Smith, O. (2010). Recommendations on terminology and practice of psychophysical DNIC testing. Eur. J. Pain 14, 339.

Younger, J., and Mackey, S. (2009). Fibromyalgia symptoms are reduced by low-dose naltrexone: a pilot study. Pain Med. 10, 663-672.

Yunus, M. B. (1984). Primary fibromyalgia syndrome: current concepts. Compr. Ther. 10, 21-28.

Yunus, M. B. (2008). Central sensitivity syndromes: a new paradigm and group nosology for fibromyalgia and overlapping conditions, and the related issue of disease versus illness. Semin. Arthritis Rheum. 37, 339-352.

Zhao, P., Waxman, S. G., and Hains, B. C. (2007). Modulation of thalamic nociceptive processing after spinal cord injury through remote activation of thalamic microglia by cysteine cysteine chemokineligand 21.J. Neurosci. 27,8893-8902.

Conflict of Interest Statement: The authors declare that the research was conducted in the absence of any commercial or financial relationships that could be construed as a potential conflict of interest.

Received: 20 October 2010; paper pending published: 22 December 2010; accepted: 09 March 2011; published online: 31 March 2011.

Citation: Smith HS, Bracken D and Smith JM (2011) Pharmacotherapy for fibromyalgia. Front. Pharmacol. 2:17. doi: 10.3389/ fphar.2011.00017

This article was submitted to Frontiers in Neuropharmacology, a specialty of Frontiers in Pharmacology.

Copyright (c) 2011 Smith, Bracken and Smith. This is an open-access article subject to a non-exclusive license between the authors and Frontiers Media SA, which permits use, distribution and reproduction in other forums, provided the original authors and source are credited and other Frontiers conditions are complied with. 